\title{
The use of kinematic hardening models for predicting tunnelling-induced ground movements in London Clay
}

\author{
V. AVGERINOS*, D. M. POTTS $\dagger$ and J. R. STANDING $\dagger$
}

\begin{abstract}
The use of a kinematic hardening soil model for predicting short- and long-term ground movements due to tunnelling in London Clay is investigated. The model is calibrated against oedometer and triaxial tests on intact samples from different units of the London Clay. The calibrated model is then used in finite-element analysis to simulate the field response at St James's Park during excavation of the Jubilee Line Extension tunnels. The finite-element predictions compare well with the available field monitoring data. The importance of using consistent initial conditions for this complex boundary value problem in conjunction with the model parameters selected is highlighted. The stiffness response of different regions of the finite-element mesh indicates that the rate at which the stiffness degrades and the stiffness response further away from the tunnel boundary affect the short-term predictions significantly. The long-term predictions confirm that the compression characteristics of the soil control the magnitude of the consolidation settlements and its permeability the shape of the long-term settlement profiles.
\end{abstract}

KEYWORDS: ground movements; numerical modelling; tunnels \& tunnelling

\section{INTRODUCTION}

Despite recent improvements in excavation techniques and ground support that modern tunnel-boring machines offer, tunnelling still causes stress relief in the ground, which leads to the surrounding soil moving towards the opening. The accurate prediction of ground surface settlement remains one of the most challenging aspects of geotechnical engineering. Various researchers have tried to address this problem either by producing empirical correlations or analytical solutions, or by numerical studies.

Peck (1969) stated that the transverse surface settlement trough above a tunnel usually has the form of a Gaussian distribution. This was also confirmed by data collected and presented by Schmidt (1969) and O'Reilly \& New (1982), who also showed an empirical correlation between the width of the surface settlement trough and the depth of the tunnel. Analytical solutions have also been produced to estimate the surface ground movements due to tunnelling. Pinto \& Whittle (2014) compared various analytical solutions proposed in the literature. They concluded that superimposing deformation modes of uniform convergence and relative distortion (Sagaseta, 1987), with the soil being treated as linear elastic or plastic with constant dilation, would result in a better approximation compared with the solution of Verruijt (1997). They also extended the solutions to take into consideration three-dimensional (3D) ground movements and the effects of soil anisotropy (Zymnis et al., 2013) which were shown to be minor. Furthermore, semi-analytical approaches have been attempted. Puzrin et al. (2012), for instance, correlated the trough width parameter with the ratio of anisotropic shear moduli by combining two different anisotropic elastic displacement fields and proposed an

Manuscript received 18 February 2015; revised manuscript accepted 12 October 2015. Published online ahead of print 4 December 2015. Discussion on this paper closes on 1 July 2016, for further details see p. ii.

* Geotechnical Consulting Group, London, UK; formerly Imperial College, London, UK;

$\dagger$ Department of Civil and Environmental Engineering, Imperial College, London, UK. alternative approach. Other researchers (e.g. Osman et al., 2006; Klar \& Klein, 2014) approached the problem from an energy calculation perspective. It is undeniable that analytical and empirical correlations are useful tools for assessing ground surface settlement troughs and have addressed various limitations. However, although they can be used as a first estimate of the short-term ground surface settlement troughs, they have limitations; the most important of these are that they do not take into consideration the non-linear behaviour of soil in the small strain range, they have a very primitive way of considering plasticity and they lack any credible long-term solution.

Over the past two decades researchers have also focused on the use of various numerical models and different aspects of soil behaviour for predicting short- and long-term ground movements due to tunnelling in stiff, overconsolidated clays, especially London Clay. The complexity of the constitutive models has steadily increased, often trying to incorporate results from advanced experimental research. Most of the analyses performed predict surface settlement troughs that are shallower and wider than those observed from field measurements.

Despite the fact that early experimental data relating to reconstituted overconsolidated clays (Jardine et al., 1984; Burland, 1990) indicated that soil behaviour is non-linear and inelastic in the small strain range, the first numerical studies of tunnelling in London Clay incorporated only non-linearity. Addenbrooke et al. (1997), for instance, showed that the introduction of pre-yield non-linearity (yield being described by the Mohr-Coulomb failure criterion) improves the comparison of numerical short-term predictions with field measurements. It was also shown that the width and depth of the predicted settlement troughs are strongly controlled by the coefficient of earth pressure at rest, $K_{0}$. The introduction of pre-yield transversely anisotropic stiffness did not improve the comparison unless unrealistic degrees of anisotropy were used. Franzius et al. (2005) performed 3D analyses and confirmed that the resulting settlement trough shape did not differ from that obtained from two-dimensional (2D) analyses and consequently the 3D aspect could not explain differences between predictions and field observations. 
Experimental research (Atkinson et al., 1990; Clayton \& Heymann, 2001) on reconstituted and intact samples of London Clay showed that the stiffness is dependent on the previous (and recent) stress history of the soil. These two studies introduced new concepts about how the previous stress history affects the stiffness response of the soil. Creep effects and the direction of the stress path with respect to the failure envelope were believed to be influencing factors. Mašin \& Herle (2005), by comparing various constitutive models in analysing a tunnelling problem, confirmed that a numerical constitutive model should be able to capture not only non-linearity at small strains and anisotropy but also the stiffness dependence on the stress path direction for realistic predictions of ground movements due to tunnelling. Grammatikopoulou (2004) developed two- and threesurface kinematic hardening models (based on the work of Al-Tabbaa \& Wood (1989) and Stallebrass \& Taylor (1997), respectively) and implemented them into the Imperial College finite-element program (ICFEP). These constitutive models allow for plasticity from early stages of loading and stiffness dependence on the stress path direction and previous stress history. In using these 'bubble' models to predict ground movements due to tunnelling in London Clay, it was shown that modelling the previous stress history considerably improved the comparison with the field measurements. This was attributed to the different stiffness responses of various elements around the perimeter of the tunnel. Grammatikopoulou's study also demonstrated that erasing the memory of the previous stress history (if modelled) deteriorates the comparison.

Hight et al. (2007), Gasparre et al. (2007a, 2007b) and Gasparre \& Coop (2008) investigated further the behaviour of London Clay. Comprehensive testing was performed on intact samples from the various units of the London Clay (King, 1981). Two major factors were identified concerning the stiffness. First, the results suggest that the elastic stiffness of the samples is considerably lower than ranges previously used for the London Clay. Second, it was found that the stiffness is affected by the previous stress history if the stress path prior to shearing crosses the Y2 surface (as defined by Jardine (1995)). Another important contribution was to develop a systematic approach to quantify the effects of structure on the behaviour of London Clay.

Mašin (2009) performed a 3D step-by-step finite-element approach to simulate the ground response to construction of the Heathrow trial tunnels using a soil model based on hypoplasticity, calibrated against the latest experimental data (i.e. Gasparre et al., 2007a, 2007b; Gasparre \& Coop, 2008; Hight et al., 2007). The comparison of the predictions with the available field data revealed a quantitative and qualitative improvement. However, the predicted ground surface settlement profiles (in both transverse and longitudinal directions) were still wider than those measured. This was attributed to the fact that anisotropy of the soil elastic stiffness was not incorporated into the version of the model used for the analysis. In the model used, the magnitude of the shear stiffness of the soil in the very small-strain and the largestrain ranges and the rate of the stiffness degradation could all be independently varied. Mašin showed that all three factors significantly influence the predicted ground displacements. Increasing the magnitude of both the small-strain and large-strain stiffnesses improved the predictions, making the settlement troughs narrower and deeper. The influence of increasing the rate at which the stiffness degrades did not show a particular trend.

González et al. (2012), using a kinematic hardening surface model, analysed the St James's Park case study (Standing et al., 1996; Nyren, 1998; Nyren et al., 2001) considering the different mechanical behaviours of the various units of the
London Clay and incorporating structure in the soil constitutive model. In their analyses four scenarios were examined, based on whether or not structure was used in their model and whether they assumed a low or high initial elastic stiffness. It was concluded that the analysis with high initial stiffness and structure gave realistic predictions of short-term ground displacements and pore water pressures. The effect of the initial stiffness was more significant compared with the effect of structure. It should be noted that despite the fact that the model used in their analyses was able to follow the previous stress history of the site, this was not done. Instead the $K_{0}$ and intrinsic preconsolidation profiles derived by Grammatikopoulou et al. (2008) for the St James's Park site were used. Additionally, even though the structure used in the model was within the available experimental range, it was quantified using an input parameter defined by the user rather than by modelling the previous stress history (to develop the field structure). As such, there is an inconsistency between the soil model parameters used and the initial conditions adopted.

According to Mair \& Taylor (1997) the main contributing factors to long-term consolidation settlements due to tunnelling are the pore water pressure distribution in the ground prior to the tunnel construction, the magnitude and distribution of the excess pore water pressures in the soil due to the tunnel construction, the soil compressibility and permeability and the relative soil-lining permeability. These have been studied by many researchers, but without relating their effect to short-term ground movements.

In this paper the two-surface kinematic hardening model (M2-SKH) developed by Grammatikopoulou (2004) is calibrated against experimental data from intact London Clay as presented by Gasparre et al. (2007a, 2007b) and Hight et al. (2007) and used to perform Class C predictions (Lambe, 1973) for the St James's Park case study. A systematic approach is followed in order to examine what influences the transverse ground surface settlement and the associated subsurface ground movements in the short term. Long-term ground movement predictions are then presented, focusing on the effects of soil permeability and discussing whether, with a single set of parameters, it is possible to predict satisfactorily ground movements in both the short and long term.

\section{DESCRIPTION OF THE NUMERICAL MODEL}

General site information

The stratigraphy and the geometry of the Jubilee Line Extension (JLE) tunnels beneath St James's Park implemented in all the analyses are presented in Fig. 1. The B2 and A3 units of the London Clay have thicknesses of $10.5 \mathrm{~m}$ and $12 \mathrm{~m}$, respectively, and below them, unit A2 extends to about $40 \mathrm{~m}$ depth and is underlain by the Lambeth Group Formation. Unit A2 was modelled with the same properties as the unit A3 as it lies below the invert of the deeper of the two tunnels and insufficient laboratory tests have been performed to assess fully its strength and stiffness properties.

The extensive monitoring system installed at the St James's Park site for monitoring ground movements during JLE tunnelling are shown in Fig. 2. Despite the fact that surface monitoring points and electrolevel inclinometers were removed in or before 1999, measurements of ground vertical displacements using rod extensometers are still taken periodically. As such, the available field data from surface and subsurface monitoring in the short and long term provide a comprehensive database against which finite-element analysis predictions can be compared and validated. 


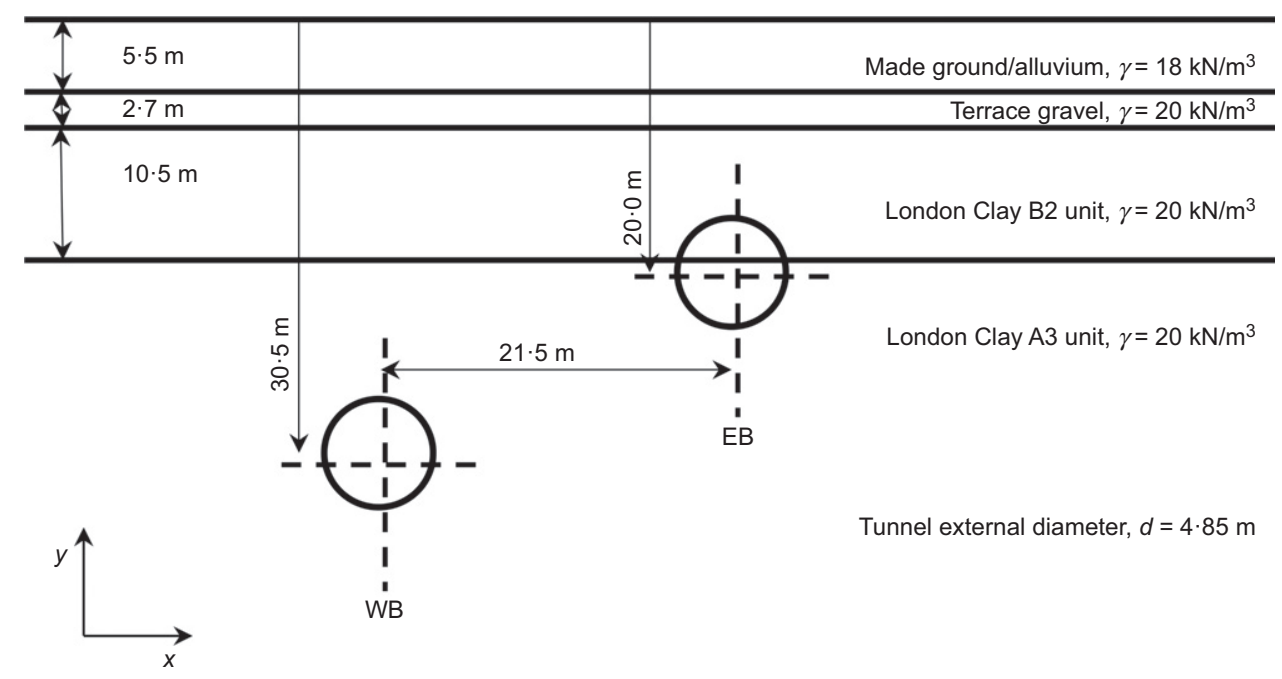

Fig. 1. Soil profile and tunnel geometry assumed at St James's Park

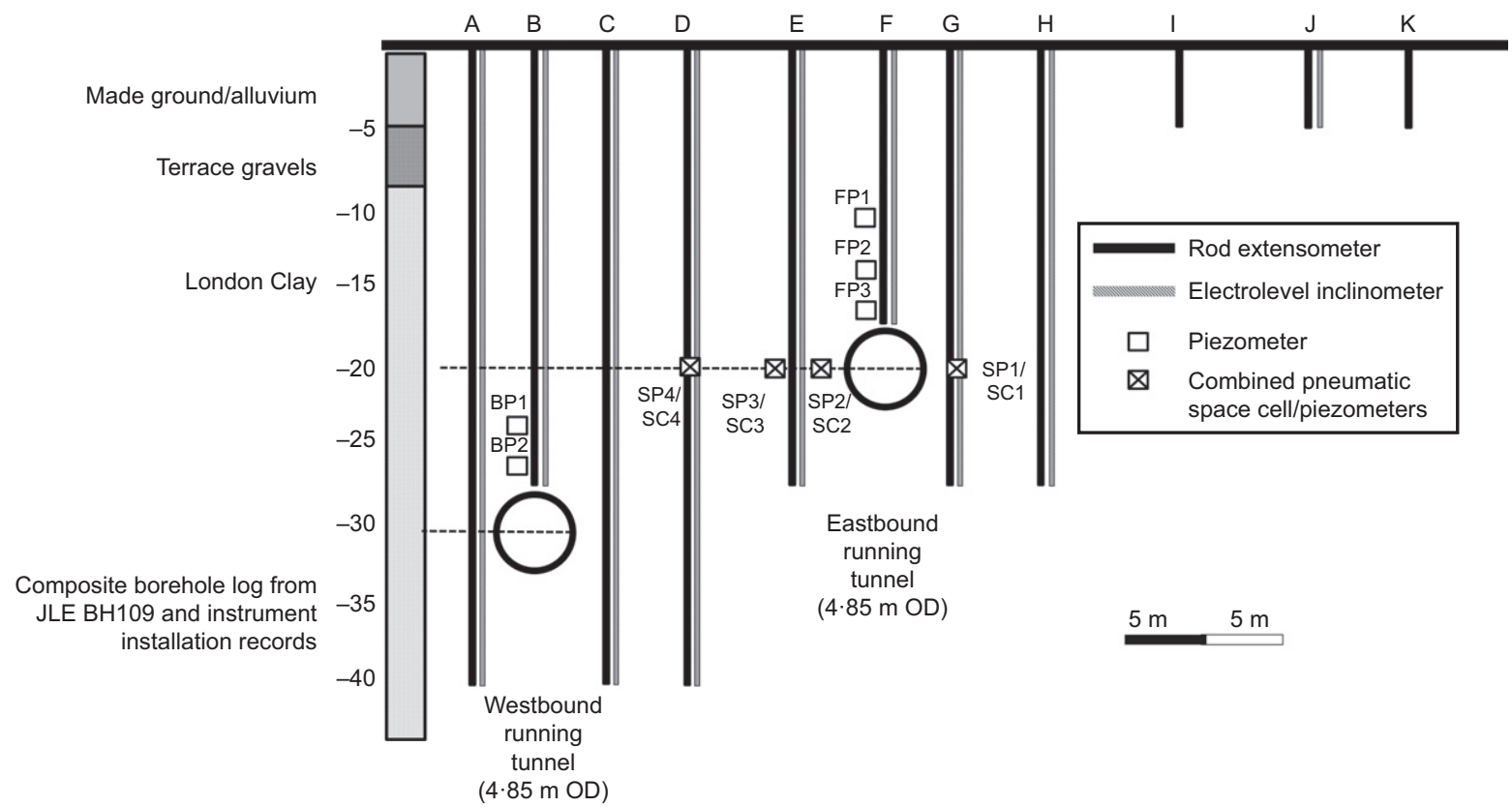

Fig. 2. Section showing the position of rod extensometers and other subsurface instrumentation at St James's Park (Nyren, 1998)

\section{Analyses performed and analysis sequence}

Various analyses were performed in order to investigate different features of the kinematic hardening model and their effect on the prediction of the ground response due to tunnelling. Four basic analyses were performed and are named after the four different calibration cases (described later in Table 1). Additionally, a series of parametric analyses was performed to examine the effect of the 'bubble' model parameter ' $a$ ' on the $K_{0}$ profile and the short-term settlement trough. A further parametric study investigated the effect of the presence of horizontal silt and sand partings in the upper part of the A3 unit (Standing \& Burland, 2006) on the long-term ground movements.

The four basic analyses involve a series of construction stages, as shown in Table 2. The previous stress history was initially modelled (based on Grammatikopoulou et al. (2008)). The westbound (WB) and the eastbound (EB) tunnel excavations and lining constructions, with an 8-month consolidation period between them, followed. The final stage was the modelling of a consolidation period up to the year 2011 (for which field data were available at the time that the analyses were performed) followed by 80 more years in order to allow for the full equilibration of the pore water pressure with the new hydraulic boundary conditions of the site. A number of solution increments was adopted for each stage in order to accommodate in an efficient way the small dimension of the 'bubble' used in the constitutive model.

\section{Analyses details}

The finite-element mesh used in the analyses is presented in Fig. 3. All the analyses performed were plane strain. As they involved coupled consolidation, the solid elements representing the London Clay have a pore water pressure degree of freedom located at each of their corner nodes in addition to the two displacement degrees of freedom at each of their eight nodes. The made ground/alluvium and the terrace gravels were modelled with non-consolidating eight-noded elements. The beam elements (simulating the tunnel linings) have three degrees of freedom (two displacements and one 
Table 1. Names of various calibrations

\begin{tabular}{l|l}
\hline Name & Tests calibrated against \\
\hline 'High* triaxial' & Reproduces stiffness from previous test data \\
'Low* triaxial' & Reproduces stiffness from Gasparre and Hight data \\
'High* both' & Uses both data from previous triaxial tests and oedometer data from T5 \\
'Low* both' & Uses Gasparre and Hight triaxial data and oedometer from T5 \\
\hline
\end{tabular}

*'High' relates to elastic stiffness from undrained triaxial tests from previous data on London Clay (Hight et al., 2007); 'Low' relates to elastic stiffness from undrained triaxial tests from Gasparre (2005) and Hight et al. (2007).

Table 2. Analysis sequence

\begin{tabular}{l|l}
\hline Increment numbers & Analysis stages \\
\hline $1-200$ & Erosion of 180 m of overburden (drained) \\
$201-210$ & Deposition of terrace gravel (drained) \\
$211-230$ & Deposition of made ground/alluvial deposit (drained) \\
$201-230$ & Increase of the water table from the top of London Clay to the top of terrace gravel \\
$231-430$ & Excavation of westbound tunnel (undrained)* \\
$431-451$ & Consolidation period of 8 months between the two tunnel constructions \\
$452-651$ & Excavation of eastbound tunnel (undrained)* \\
$652-688$ & Consolidation period up to 2011 (14 years) \\
$689-705$ & Consolidation period for 80 years \\
\hline
\end{tabular}

*Construction of the tunnel linings took place in different increments during their excavation for each set of calibration parameters.

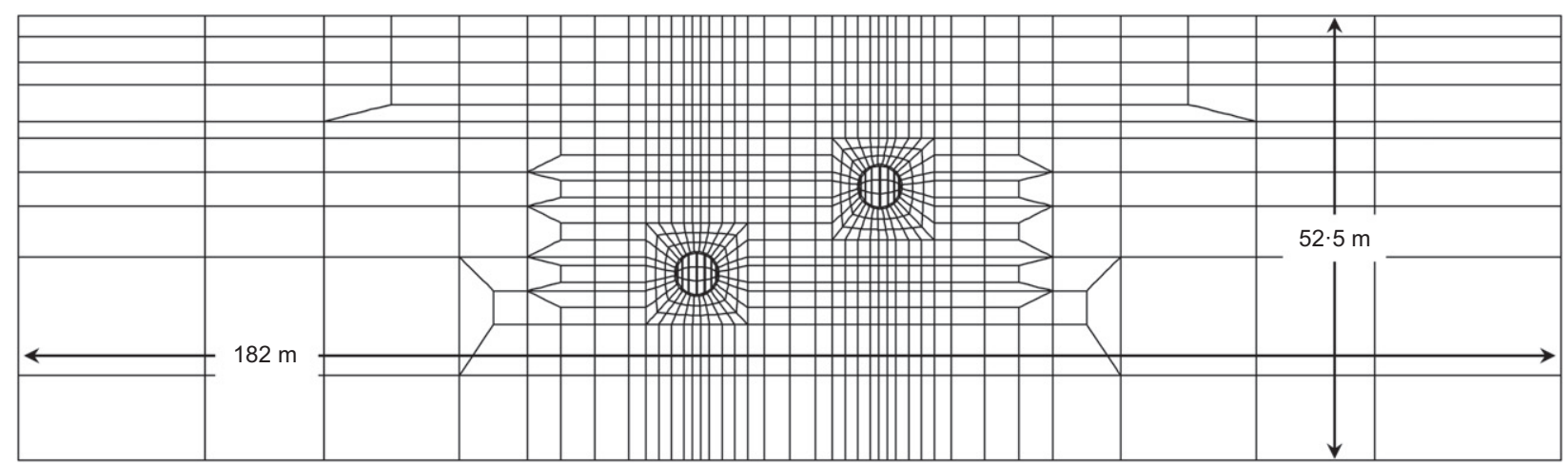

Fig. 3. Finite-element mesh

rotation) at each of their three nodes. In all the analyses $2 \times 2$ integration was used and a modified Newton-Raphson technique was implemented as the non-linear solver (Potts \& Zdravković, 1999).

The made ground/alluvium was modelled as a linear elastic material having a Young's modulus $E=5000 \mathrm{kPa}$ and Poisson ratio $\mu=0 \cdot 3$ and the terrace gravel with a non-linear elastic-plastic model (with the parameters proposed by Addenbrooke et al. (1997)) incorporating a Mohr-Coulomb yield surface with the angle of internal shearing resistance, $\varphi^{\prime}=35^{\circ}$ and the angle of dilation, $v=17 \cdot 5^{\circ}$. The modified two-surface kinematic hardening model, M2-SKH (Grammatikopoulou, 2004), was used to model the London Clay units B2 and A3 (see calibration below) with the latter assumed to extend to the base of the finite-element mesh.

During each analysis the bottom boundary of the finiteelement mesh (located $52.5 \mathrm{~m}$ below the ground surface) was fixed in both the vertical and horizontal directions, whereas the vertical boundaries were fixed only in the horizontal direction. Concerning the hydraulic boundary conditions, all boundaries of the London Clay were left free to drain (fixed pore water pressures). For the tunnels (constructed using expanded precast concrete segments with no grouting and no special water proofing measures), a precipitation boundary condition was used. This enabled a zero pore water pressure or a zero flow boundary condition to be applied at individual nodes around the tunnel periphery depending on whether the analysis indicated drainage into the tunnel or flow out of the tunnel at these nodes, respectively. The excavations of the tunnels were simulated using the volume loss control method (Potts \& Zdravković, 2001). The linings were installed as soon as the desired volume loss of $3 \cdot 3 \%$ and $2 \cdot 9 \%$ was achieved for the WB and the EB tunnels, respectively.

For each analysis an anisotropic permeability model was used where the permeability horizontally is twice that vertically. The permeability profile used is shown in Fig. 4, which compares well with available field data from different sites in London.

According to Standing \& Burland (2006) water strikes occurred in all the boreholes drilled in St James's Park within the top 5-6 m of London Clay A3 unit. At this depth, high concentrations of sand and silt partings were encountered, indicating that this 'sub-unit' has a high permeability. This sub-unit, which they denoted $\mathrm{A} 3_{\text {II }}$, is consistent throughout the London Clay formation. In order to take this into account in the parametric analyses performed, the permeability profile was altered over the upper $5 \mathrm{~m}$ of the A3 unit with the vertical permeability increased to a constant 


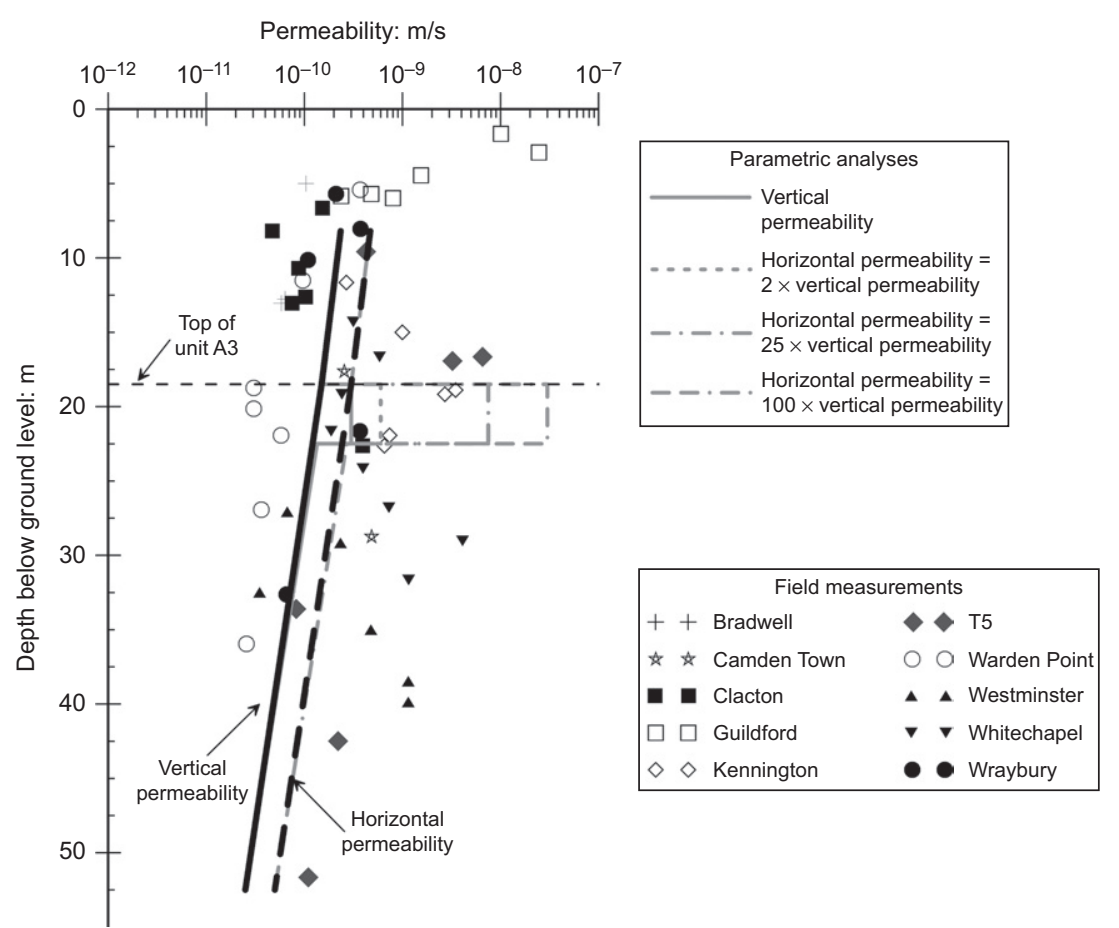

Fig. 4. Different permeability profiles used for the London Clay

Table 3. List of model parameters derived for each calibration

\begin{tabular}{|c|c|c|c|c|}
\hline \multirow[t]{2}{*}{ Model parameters } & 'Low triaxial' & 'High triaxial' & 'Low both' & 'High both' \\
\hline & \multicolumn{4}{|c|}{ (unit B2/unit A3) } \\
\hline$V_{1}$ & $2 \cdot 5 / 2 \cdot 75$ & & & \\
\hline$\lambda$ & $0 \cdot 12 / 0 \cdot 15$ & & & \\
\hline$\kappa$ & $0 \cdot 06 / 0 \cdot 063$ & & & \\
\hline$n$ & $0 \cdot 87$ & & & \\
\hline$m$ & $0 \cdot 28$ & & & \\
\hline$A$ & $250 / 180$ & $550 / 455$ & $260 / 190$ & $550 / 455$ \\
\hline$\varphi^{\prime}$ & $25^{\circ} / 20 \cdot 3^{\circ}$ & & & \\
\hline$R$ & $0 \cdot 01 / 0 \cdot 005$ & $0 \cdot 016 / 0 \cdot 005$ & $0 \cdot 02 / 0 \cdot 005$ & $0 \cdot 016 / 0 \cdot 05005$ \\
\hline$a$ & $0 \cdot 8$ & $1 \cdot 2$ & $1 \cdot 5$ & $2 \cdot 5$ \\
\hline
\end{tabular}

value of $3 \times 10^{-10} \mathrm{~m} / \mathrm{s}$ and a varying degree of anisotropy of 2, 25 and 100, as shown in Fig. 4.

\section{CALIBRATION OF THE 'BUBBLE' MODEL}

Different calibrations of the 'bubble' model, summarised in Table 1, were performed for the London Clay units. The calibration is based on the findings from research on the intact properties of the London Clay from the Heathrow terminal 5 (T5) project (Gasparre, 2005; Hight et al., 2007) and older published data available for the London Clay. Tests from T5 indicated a lower range of elastic stiffness values than those previously established for the London Clay. As such, isotropically consolidated undrained triaxial compression tests and oedometer tests on intact samples of units B2 and A3 (Gasparre, 2005; Hight et al., 2007) were simulated. The calibration cases were divided into 'low' and 'high' depending on which elastic stiffness they reproduced. In addition each one of these two cases was further subdivided into two categories. The 'triaxial' cases reproduced the stiffness degradation from the triaxial tests well, but neglected completely how they perform in terms of oedometer test results, while the 'both' aims to obtain a compromise between the triaxial and the oedometer results.

The London Clay model parameters adopted in each calibration are listed in Table 3 with most of them being obtained from the original test data. The slope of elastic swelling lines $\left(\kappa_{\mathrm{e}}\right)$ is one input model parameter. When values of $\kappa_{\mathrm{e}}$, as reported by Hight et al. (2007), were used, the simulation of the triaxial tests showed unrealistic peak strengths. Consequently a higher value was adopted which represented an average value over the unloading part of the oedometer tests. The size of the 'bubble' was less than $2 \%$ of that of the bounding surface and the yield stress ratio used in the calibration exercise was within the ranges given by Gasparre (2005) for each sample. The hardening term coefficient $(a)$, which controls how fast the stiffness decays, was calibrated last. This parameter cannot be directly correlated with any soil property that can be measured from conventional or advanced laboratory testing. As such, different values were tried and the stiffness degradation curve of a single element under undrained triaxial compression was compared with the laboratory tests. It was observed that the smaller the value of ' $a$ ', the steeper the degradation of the curve beyond the elastic range. The value chosen for each 


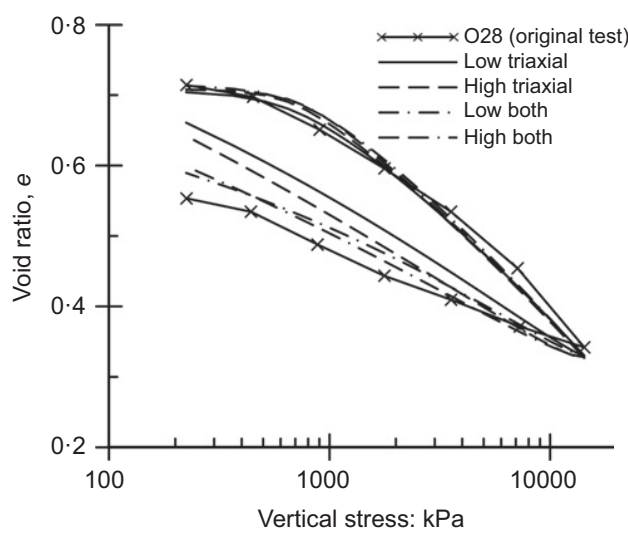

(a)

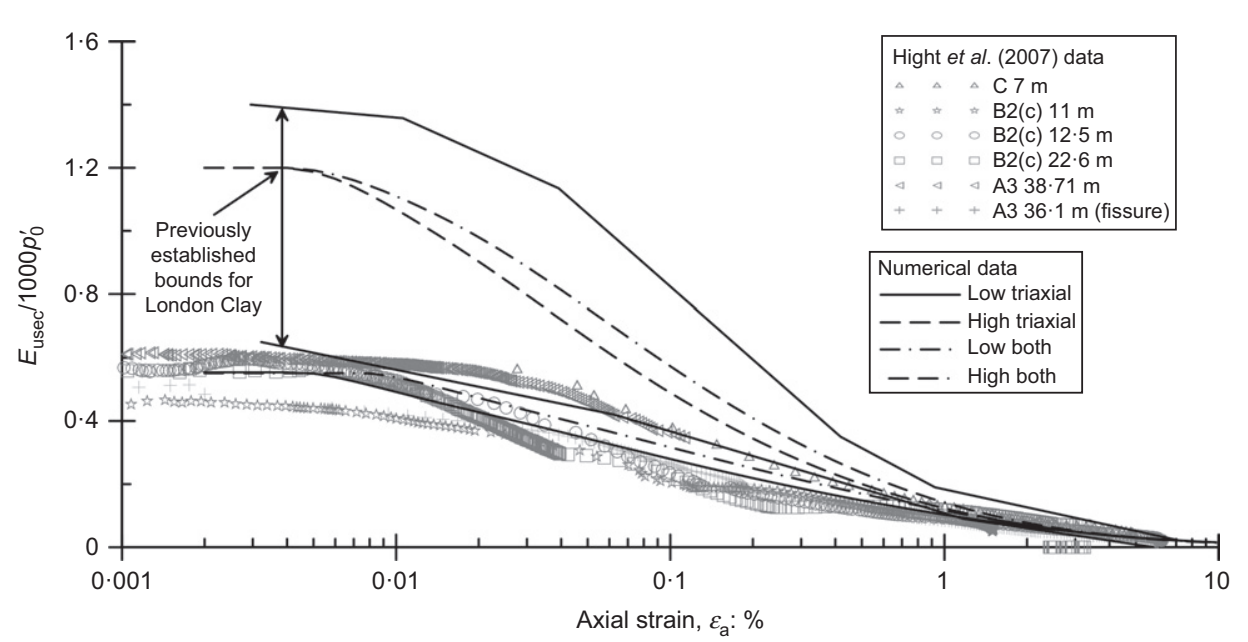

(c)

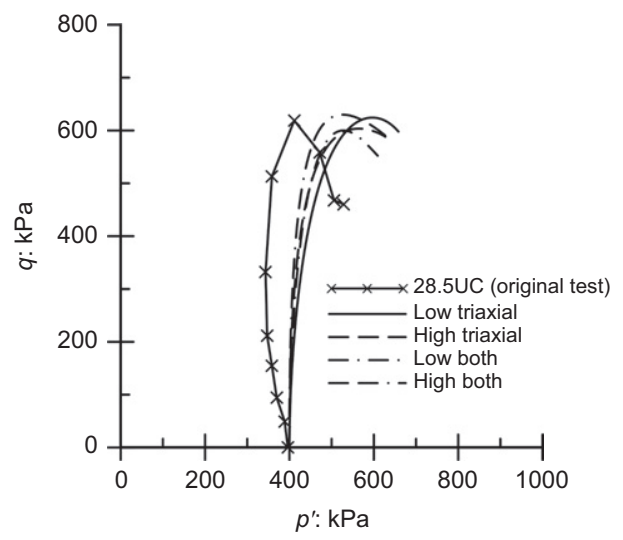

(b)

a) oedometer test: void ratio-effective stress response; (b) triaxial test:

Fig. 5. Original tests and calibration results for
stress path; (c) triaxial test: stiffness response

calibration case was ultimately selected on a best-fit basis rather than on any optimisation procedure.

The predicted response of the oedometer and the triaxial compression tests (in terms of both stress path and stiffness degradation) is shown in Fig. 5 for unit B2. Similar results were obtained for unit A3. It is evident that the 'triaxial' cases do not predict satisfactorily the swelling part of the oedometer data but the triaxial tests were simulated well. The 'both' cases, on the other hand, predict slightly better the oedometer tests, while they also predict a stiffer response for a wide range of strains compared with the respective 'triaxial' cases. The calibration reveals that the model struggles to predict satisfactorily both shearing and compression responses with the same set of parameters.

\section{$K_{0}$ PROFILE PRIOR TO THE WB EXCAVATION}

The coefficient of earth pressure at rest, $K_{0}$, has a significant influence on the short-term response of stiff overconsolidated clays due to tunnelling. Fig. 6 shows the $K_{0}$ values used for each analysis before the WB tunnel excavation. These profiles were developed from modelling the previous stress history and are compared with the prediction of $K_{0}$ using the expression given by Mayne \& Kulhawy (1982).

The predicted profiles result in generally low values of $K_{0}$. Burland et al. (1979) concluded that the distribution of $K_{0}$ with depth is not unique and is very sensitive to stress history. The reloading stage at St James's Park involved the deposition of $8.2 \mathrm{~m}$ of superficial deposits (following the erosion of $180 \mathrm{~m}$ of London Clay). Avgerinos (2014) reran the previous

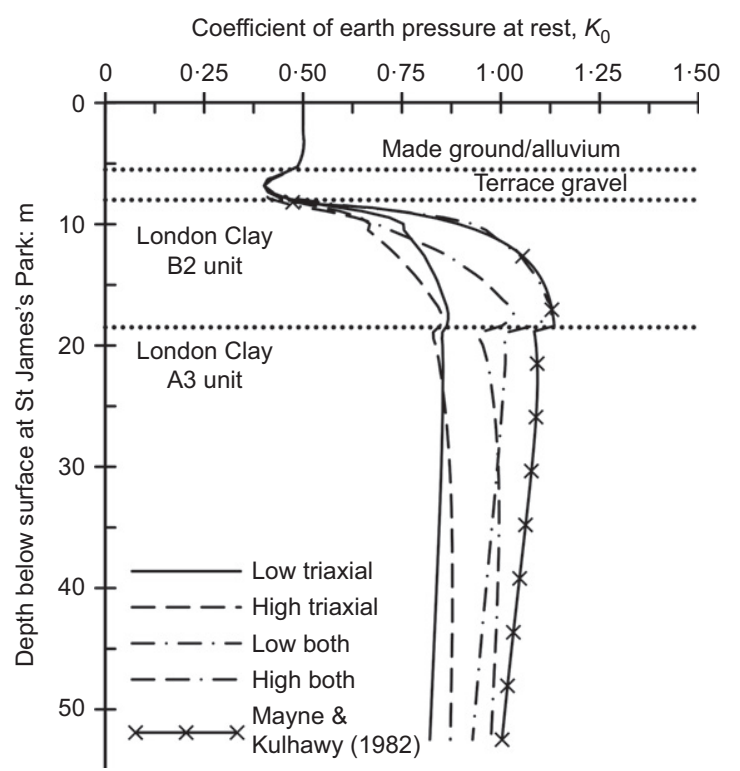

Fig. 6. $K_{0}$ profiles with depth obtained from the four calibration cases

stress history increments of the analysis using a reduced thickness of superficial deposits (just $6 \mathrm{~m}$ ) and this resulted in higher values of $K_{0}$, which compared well with the field data from sites with the same thickness of superficial deposits. Different profiles resulted from the four calibration cases and for varying thicknesses of superficial materials, 
highlighting the difficulty and importance of using a consistent $K_{0}$ profile based on the history of the site and the parameters adopted for the 'bubble' model.

\section{SHORT-TERM RESPONSE DUE TO WB JLE TUNNEL CONSTRUCTION \\ Surface settlement trough}

The short-term ground movements due to the WB JLE tunnel were measured and described by Standing et al. (1996), Nyren (1998) and by Nyren et al. (2001). The volume loss measured for this tunnel was $3 \cdot 3 \%$ and each of the analyses (using the different sets of parameters) adopted this value as a target volume loss. Table 4 summarises the volume loss calculated by integrating the radial displacement around the tunnel periphery and the associated unloading percentage. Overall, the latter is considered to be low while it is directly related to the initial elastic stiffness with higher initial elastic stiffness values resulting in higher degrees of unloading.

Figure 7(a) presents the predicted surface settlement troughs above the WB tunnel for all the calibration cases examined and their comparison with the field data. All of the new sets of parameters adopted for the London Clay result in a much deeper settlement trough, improving the match with the field data compared with previous studies. The settlement trough predicted by Grammatikopoulou (2004), where reconstituted soil test data were used to calibrate the 'bubble' model, is also superimposed in the figure. The maximum settlement varies from 15.4 to $18.6 \mathrm{~mm}$ compared to the value of $20.4 \mathrm{~mm}$ that was measured in the field (i.e. $8 \cdot 8 \%$ to $23 \cdot 5 \%$ difference). The analysis using the old calibration parameter values gives a maximum settlement of $11.3 \mathrm{~mm}$ (Grammatikopoulou et al., 2008). Clearly a definite improvement in terms of maximum settlement is achieved with the new calibration parameter values for the same constitutive model. The improvement is also obvious in terms of the

Table 4. Values of volume loss and percentage of unloading

\begin{tabular}{l|c|c}
\hline Analysis & $\begin{array}{c}\text { Volume loss from radial } \\
\text { displacement: } \%\end{array}$ & Unloading: \% \\
\hline Low triaxial & $3 \cdot 39$ & $13 \cdot 5$ \\
High triaxial & $3 \cdot 38$ & $23 \cdot 5$ \\
Low both & $3 \cdot 40$ & $26 \cdot 5$ \\
High both & $3 \cdot 37$ & $37 \cdot 0$ \\
\hline
\end{tabular}

shape of the trough, as can be judged by the normalised settlement troughs in Fig. 7(b). Reasonable agreement with the field data is obtained for the cases where the calibration is based on a compromise of both the triaxial test data and the oedometer unloading path. However, the best predictions are achieved for the other two cases where the oedometer unloading path is neglected. The improvement is significant, resulting in much narrower troughs compared with that obtained using previous parameter values adopted by Grammatikopoulou et al. (2008) for London Clay. It can be also observed that the troughs are not significantly affected by whether the initial high or low elastic stiffness calibration models were adopted. It is the spatial discretisation of stiffness (with depth and with distance from the tunnel boundary) that plays the most significant role for the short-term ground surface troughs. The respective predictions relating to the EB tunnel excavation are given by Avgerinos (2014).

\section{Stiffness response}

As discussed by Grammatikopoulou et al. (2008) the configuration of the kinematic surfaces at the end of the previous stress history is such that elements subjected to compression yield a softer response compared with elements experiencing extension. This is confirmed by the stiffness response of an element above the crown and one next to the springline of the tunnel for the 'low triaxial' analysis due to the tunnel excavation shown in Fig. 8 in terms of incremental shear stiffness $\left(G_{\text {oct }}=\left(\Delta J / \Delta E_{\mathrm{d}}\right)\right)$ normalised by mean effective stress prior to the excavation $\left(p^{\prime}\right)$. In this figure the line labelled 'bvp' (boundary value problem) relates to the response of these elements during excavation of the tunnel. Single element tests with the same initial conditions and a centred 'bubble' around the stress state are also superimposed in the figure. The single element test modelling an element above the crown of the tunnel is subjected to undrained extension, while the single element test modelling an element next to the tunnel axis experiences undrained compression. It is clear that the stiffness degradation curve for the elements of the boundary value problem that experience stress path rotation (above the tunnel crown) is almost identical to that relating to the single element tests; this implies that the elements of the boundary value problem behave according to the calibration. The element next to the springline shows a much softer response as a consequence of taking into account the previous stress history. The simulation of an

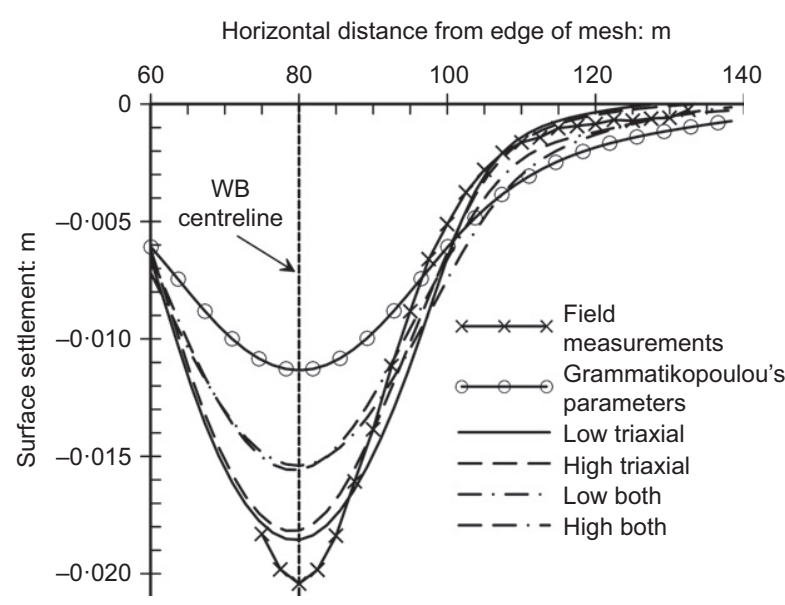

(a)

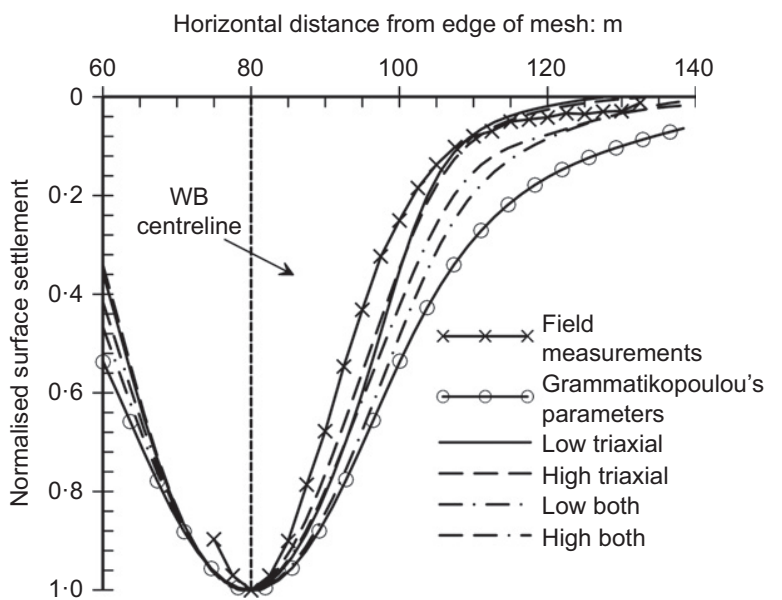

(b)

Fig. 7. (a) Surface and (b) normalised surface settlements profiles due to WB tunnel excavation 

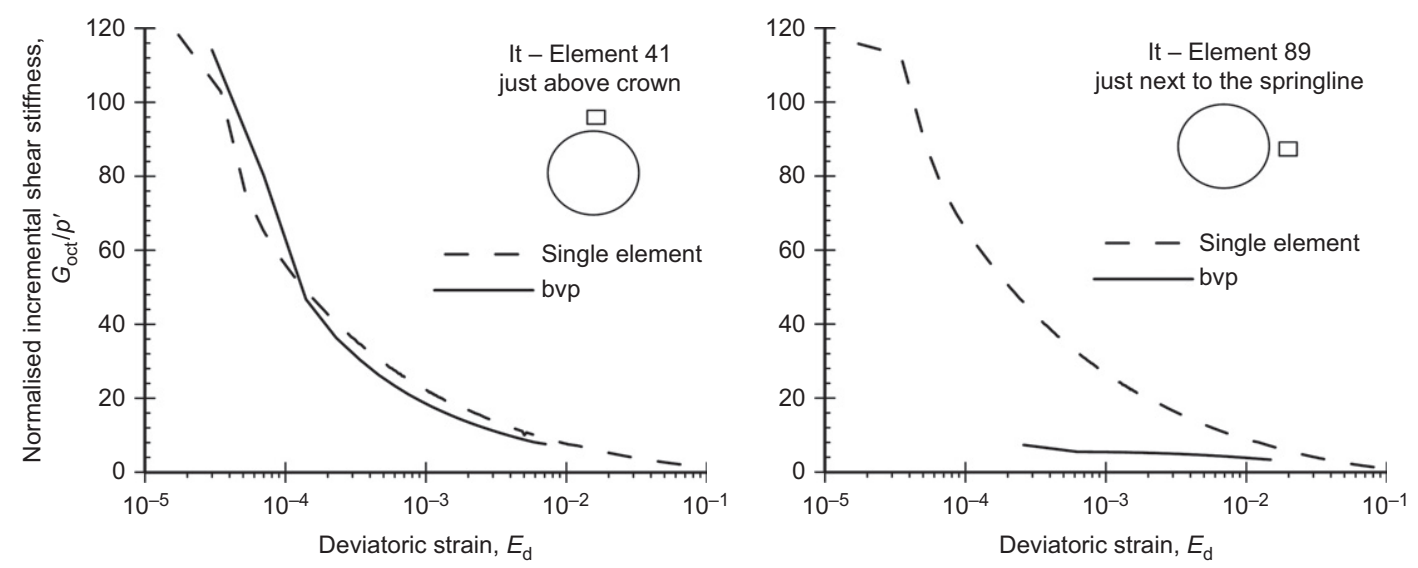

Fig. 8. Normalised stiffness-strain curves for an element of the boundary value problem (bvp) and a respective single element run relating to positions above crown and next to the springline of the tunnel for the 'low triaxial' (It) calibration case

element above and next to the tunnel with a single element is simplistic and is used to highlight that the stiffness response of an element that experiences stress rotation is accurately predicted by the 'bubble' model. Neither the elements from the boundary value problem nor the single elements consider the $3 \mathrm{D}$ nature of the tunnelling problem. The stress path that an element may experience as the tunnel approaches, reaches and passes beyond it may vary significantly and this will lead to a different stiffness response. This could be captured in a 3D finite-element model using the 'bubble' soil model to simulate the soil's behaviour.

Similar responses are obtained for all the calibration cases, as shown in Fig. 9, where the ratios of the incremental shear stiffness of the element above the crown to the incremental shear stiffness of the element next to the springline for all the cases are presented. The figure illustrates that the rate at which this ratio decreases is similar for all the cases, indicating that it is the magnitude of stiffness that various elements experience that controls the shape of the surface troughs.

Incremental shear stiffness is plotted against deviatoric strain (due to tunnel excavation) in Fig. 10 for all four calibration cases for an element of the mesh just above the tunnel crown ( $1.68 \mathrm{~m}$ above) and another further above (14.4 $\mathrm{m}$ above). The stiffness of the element which is close to the tunnel starts degrading immediately once the excavation starts and for all four cases it drops to approximately the same value (2000 to $4000 \mathrm{kPa})$ at the end of the excavation experiencing similar levels of deviatoric strain. In the case of the element that is further above, it initially behaves elastically for different degrees of deviatoric strain for each calibration case, before the stiffness starts to degrade. As a result, at the strain range where the desired volume loss was achieved, different stiffness values are mobilised. Deeper and narrower settlement troughs are captured for the cases where the loss of stiffness is greater and the initial elastic region is smaller. This reveals that the different settlement troughs predicted using the four calibration cases may be partly attributed to variations in the stiffness response of elements which are further away from the tunnel.

In order to investigate further the effect of the stiffness degradation curves, a parametric analysis was performed based on the properties of the two cases that predict high elastic stiffness (i.e. 'high triaxial' and 'high both') varying the parameter ' $a$ ' of the 'bubble' model which controls the rate of stiffness degradation after the elastic range. Analyses using a single element representing an undrained triaxial test were performed varying this parameter from $1 \cdot 2$ to $2 \cdot 5$. The

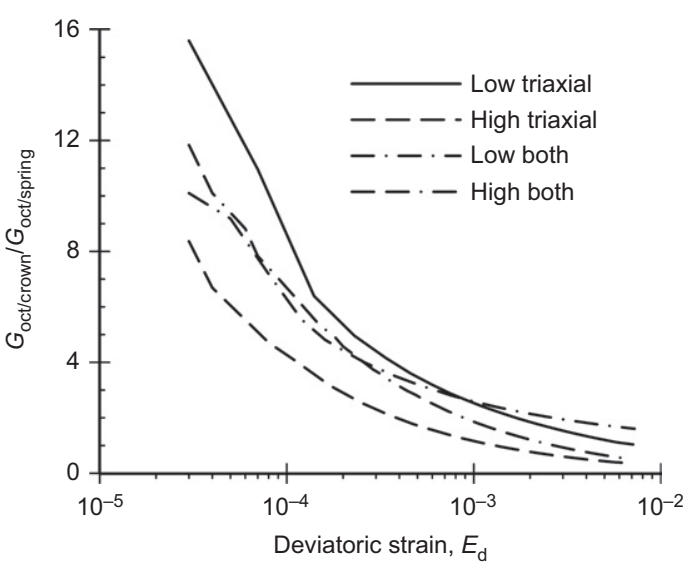

Fig. 9. Relative incremental shear stiffness in extension over compression during the tunnel excavation for all four calibration cases

variations of normalised stiffness with strain are plotted in Fig. 11. The respective $K_{0}$ profiles after the modelling of the previous stress history, from additional analyses, are shown in Fig. 12 for the four cases. The higher the ' $a$ ' value, the less steep the degradation and the stiffer the response over the entire non-elastic strain range and the higher the resulting $K_{0}$ values. It is remarkable that only a small change of ' $a$ ' results in a significant change in the $K_{0}$ profile, implying that this parameter strongly controls the initial conditions prior to tunnel excavation.

As expected (since different ' $a$ ' values result in different $K_{0}$ profiles) varying ' $a$ ' affects both the width and depth of the settlement troughs, as shown in Fig. 13. The lower the value of ' $a$ ' the deeper and narrower the settlement trough becomes. This demonstrates how important it is when using a kinematic hardening model, like M2-SKH, to use a $K_{0}$ profile which is consistent with the model parameters adopted.

In addition to the above parametric analyses, another analysis was performed in order to isolate the effect of the parameter ' $a$ ' on the predicted ground settlement trough due to tunnel excavation and distinguish it from its effect on $K_{0}$. After modelling the previous stress history using the 'high triaxial' calibration, the parameter ' $a$ ' was replaced with the value corresponding to the 'high both' calibration (i.e. ' $a$ ' changed from $1 \cdot 2$ to $2 \cdot 5$ ). By performing this change, the excavation procedure in the new analysis termed as 'high both from high triaxial' in Fig. 14 has exactly the same initial conditions as the 'high triaxial' one. As such, the difference 


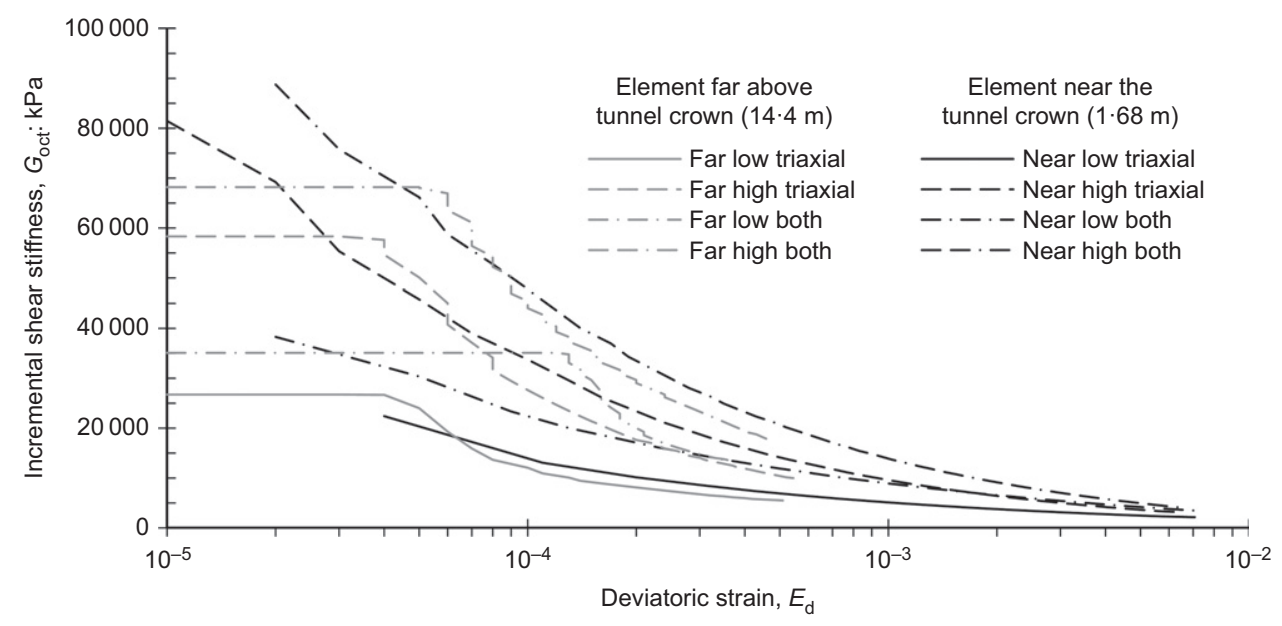

Fig. 10. Incremental shear stiffness plotted against deviatoric strain due to tunnel excavation

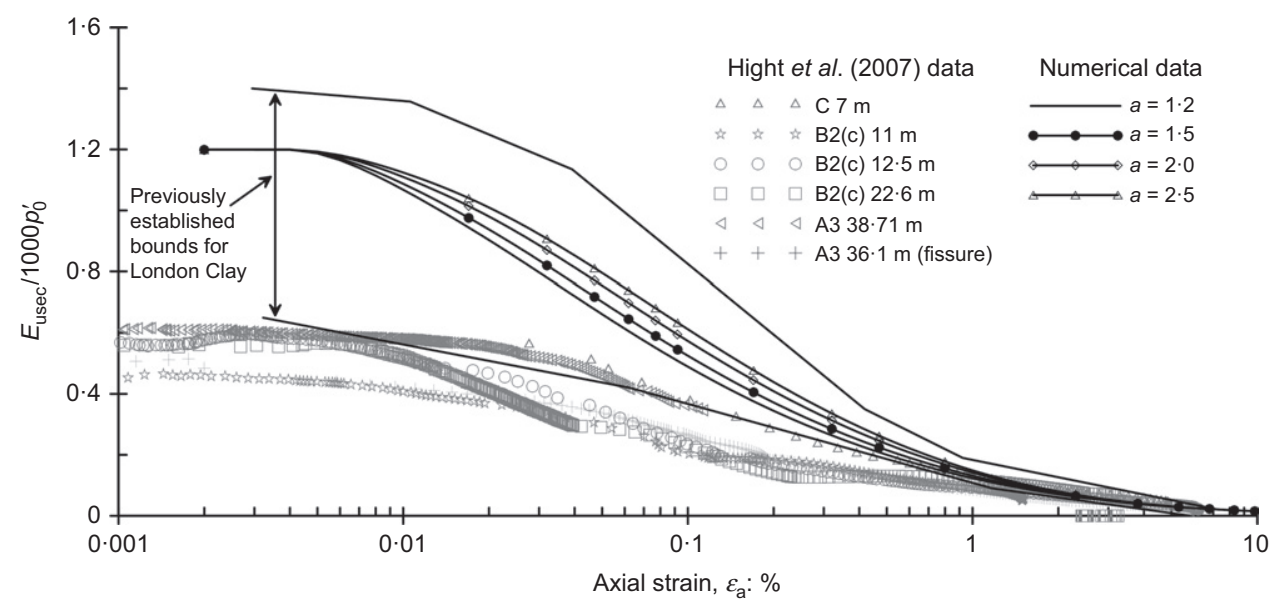

Fig. 11. Stiffness degradation curves with different ' $a$ ' values for unit B2

between these two analyses in terms of the ground settlement trough can solely be attributed to the effect of ' $a$ '. The difference of the new analysis and the 'high both' case reflects the effect of ' $a$ ' on $K_{0}$ and subsequently the settlement trough. It is clear that not only does $K_{0}$ affect the width and depth of a settlement trough in stiff, overconsolidated clays (a well-known fact), but also the way the constitutive model predicts the stiffness change with strain.

\section{Subsurface movements}

Figure 15 presents the profiles of vertical displacements with depth predicted by the finite-element analyses compared with the field measurements (obtained from extensometers at the same locations A, B and C; Nyren (1998), see Fig. 2). The model predicts the trend of the increasing vertical movements with depth with good agreement with the measured values for the three locations. All four cases are able to capture the maximum displacement, which is just above the tunnel crown (note that field measurements between this level and the base of extensometers $\mathrm{A}$ and $\mathrm{C}$ are not shown, as intermediate anchors were not installed). This can be attributed to the fact that the soil stiffness close to the tunnel drops to almost the same value for all the examined cases and as such the soil behaviour does not differ significantly between each of the cases. Furthermore, when the calibration is based on both the triaxial and oedometer test results the analyses predict less vertical displacement near to the ground surface and give a distribution which slightly under-predicts the vertical movements compared with the field measurements. The agreement between prediction and field measurement is excellent when the 'low triaxial' parameters are used; if the 'high triaxial' parameters are used, however, the numerical results slightly over-predict the field measurements. However, it is clear again that there is not a significant difference between the 'low triaxial' and 'high triaxial' results in this situation.

Another important feature of the numerical predictions is that, for all calibration cases, heave is predicted for the soil below the tunnel invert. The vertical movements only become negligible (practically zero) at a distance of 5 to 6 times the radius of the tunnel (around $50 \mathrm{~m}$ below ground level). This is corroborated by the St James's Park's field measurements when analysed using different deep datum points (Salamanca Gallo, 2005). The fact that the excavation provoked movements to depths greater than the deepest anchor in the near vicinity of the WB tunnel highlights the importance of selecting an appropriate datum for field measurements of ground response due to tunnelling.

A series of electrolevel inclinometers (Nyren, 1998) was installed within boreholes as part of the comprehensive monitoring of the St James's Park site. Fig. 16 shows the horizontal displacements along the line C ( $4 \mathrm{~m}$ to the east of 


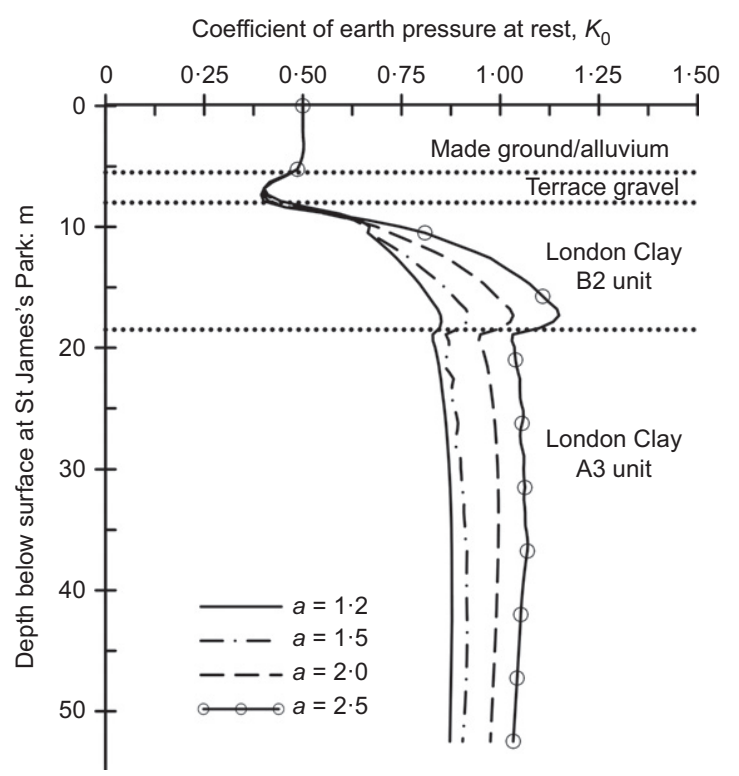

Fig. 12. Variation of $K_{0}$ with depth for different values of parameter ' $a$ '

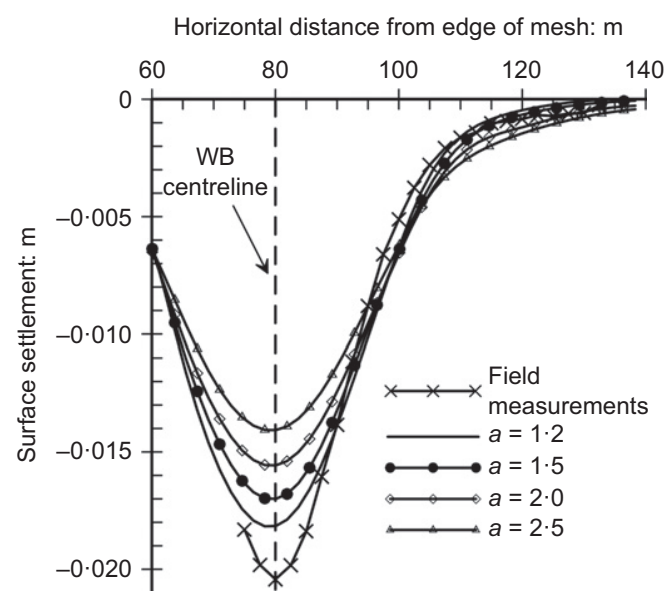

Fig. 13. Surface settlement troughs due to WB tunnel excavation for various values of parameter ' $a$ '

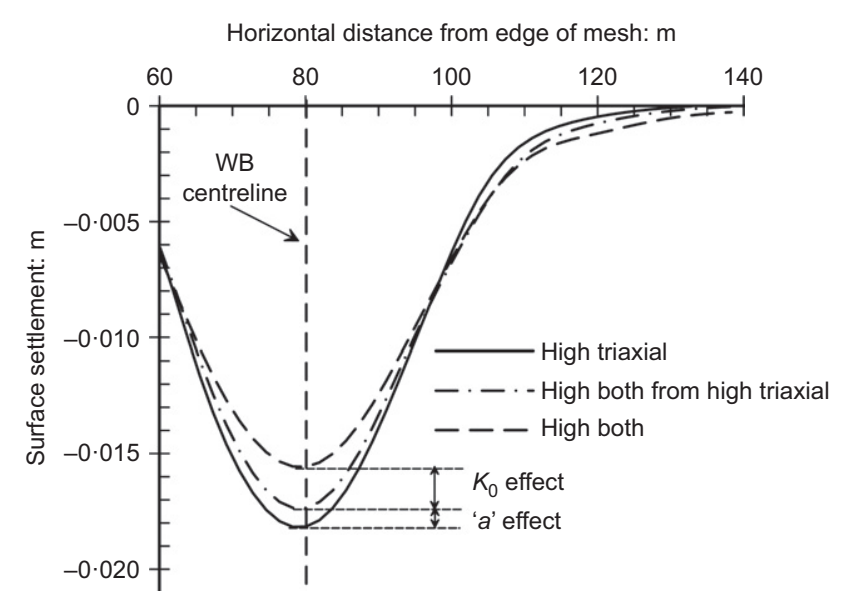

Fig. 14. Predicted settlement troughs for cases where the effect of parameter ' $a$ ' on the settlement trough is isolated the WB tunnel axis). The distributions predicted by the numerical analysis, were tied to the same absolute reference as the measured ones, which for this location is at $41 \mathrm{~m}$ below the ground surface. This is why some horizontal movement is predicted towards the bottom of the mesh. Despite the poor agreement over the first $20 \mathrm{~m}$, the numerical results compare quite well with the field measurements below this level and above the axis of the tunnel $(30.5 \mathrm{~m})$. It is noted that the field measurements over the first $20 \mathrm{~m}$ below the ground surface show (unrealistic) movement of the ground away from the tunnel. Moreover, as explained by Nyren (1998), because the electrolevels measure tilt at discrete points, significant errors arise during processing the measured data if the displacement gradient changes rapidly between adjacent instruments and extrapolating measured tilts over large gauge lengths can also produce spiked profiles. This is the situation at around $30.5 \mathrm{~m}$ where the field measurements show a spike which cannot be reliably compared with the finite-element predictions.

\section{LONG-TERM SOIL MOVEMENTS \\ Subsurface vertical movements}

Profiles of vertical movement along a horizontal line $5 \mathrm{~m}$ below ground level were measured by rod extensometers at various stages after the WB construction. In Fig. 17 these measurements are compared with the finite-element predictions for all the calibration cases. All the results (field measurements and numerical predictions) are related to the base of borehole D (see Fig. 2) assuming that this point (40 $\mathrm{m}$ below ground level) is not moving.

Just prior to the construction of the EB tunnel, 235 days after the WB tunnel construction, it is noted that the shape of the vertical movement profile is well predicted for all four calibration cases. Its magnitude is over-predicted for the calibrations based on the triaxial tests only ('low triaxial' and 'high triaxial'), whereas it compares well with the field measurements for the remaining two calibration cases ('low both' and 'high both').

After the construction of the EB tunnel it is noted that the maximum settlement was not measured directly above the EB tunnel axis but at about $5 \mathrm{~m}$ towards the WB tunnel, reflecting the disturbance of the ground between the two tunnels due to the earlier excavation of the WB tunnel. All of the analyses produce reasonable comparisons with the field data. The analyses using the 'both' cases give better predictions in terms of the shape between the two tunnels with the 'high both' case predicting even the magnitude. However, for all four cases, east of the EB tunnel axis there are discrepancies between the numerical predictions and the field measurements. The numerical predictions indicate rapidly diminishing troughs, with their widths not widening and extending eastwards as observed from the measurements.

This trend of predicting narrower troughs (compared to the field measurements) is also noted in the longer term (1997, 2006 and 2011). The magnitude of the settlement between the axes of the two tunnels is markedly overpredicted for the 'triaxial' cases, and is marginally under- and over-predicted for the 'high both' and 'low both' case. It could be said that the 'low both' over-predicts to the same degree as 'high both' under-predicts.

The two calibration cases based only on the triaxial tests fail to predict the shape change of the trough for all the cases and significantly over-predict the movements. The numerical predictions reveal that the consolidation behaviour of the London Clay is important for meaningful long-term predictions, confirming that the 'bubble' model needs to be carefully calibrated against oedometer test results. Regardless of 


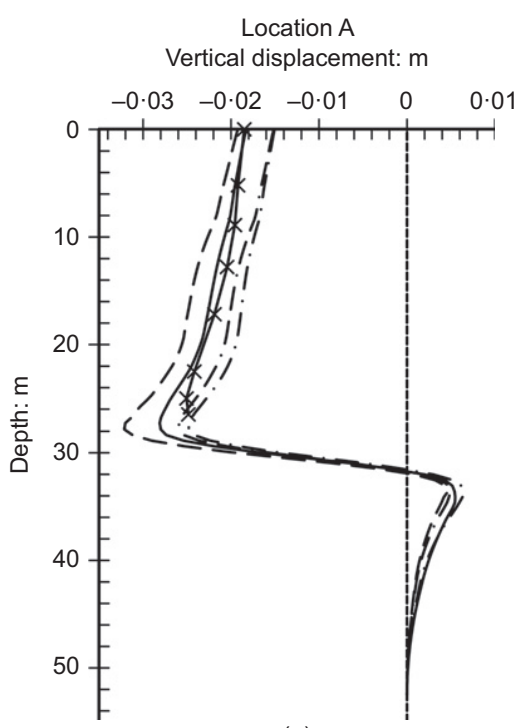

(a)
Location B Vertical displacement: $\mathrm{m}$

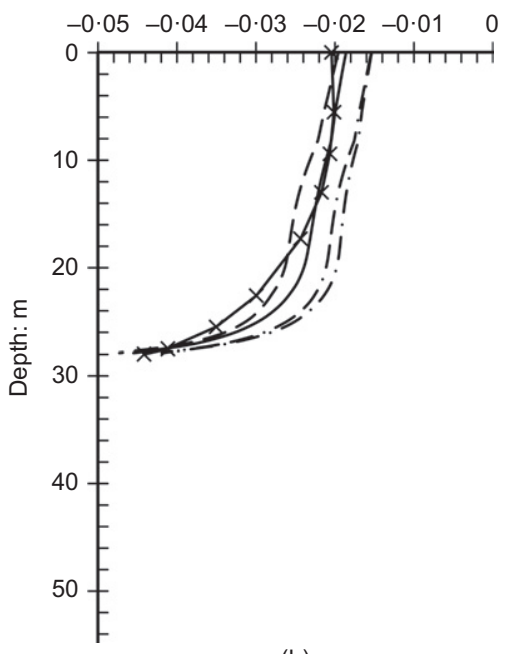

Location C Vertical displacement: $\mathrm{m}$

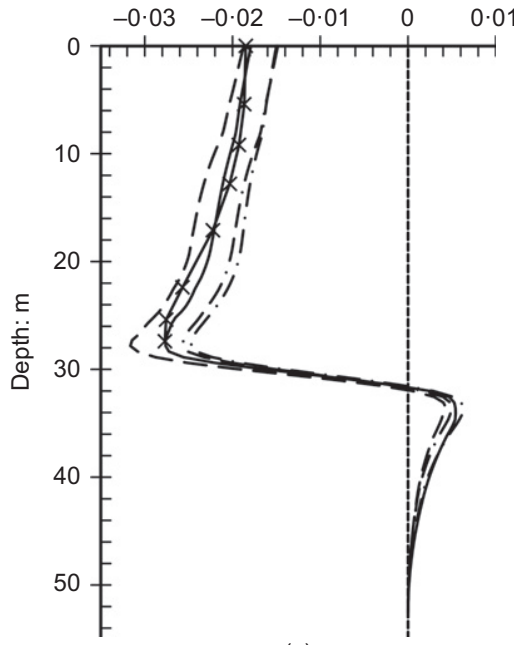

(c)

(b)

Fig. 15. Distribution of vertical displacements with depth due to WB tunnel excavation at (a) $4 \mathrm{~m}$ west, (b) directly above and (c) $4 \mathrm{~m}$ east from its axis

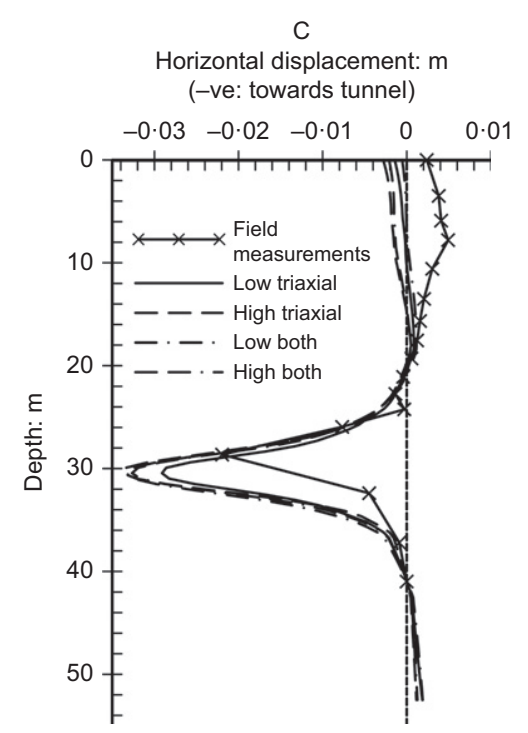

Fig. 16. Distribution of horizontal displacements with depth due to WB tunnel excavation at position C (see Fig. 2)

this, the form of the long-term settlement profile eastwards away from the tunnel axes seems not to be controlled by the calibration.

\section{Effect of unit A3 permeability}

In order to investigate the effect of the presence of higher concentrations of sand and silt partings within unit $\mathrm{A} 3_{\mathrm{II}}$ on the width of the long-term settlement trough, parametric analyses varying the degree of permeability anisotropy for this sub-unit were performed (see Fig. 4). The 'high both' calibration was used in all these analyses. This calibration was more promising compared with the 'low both' case since consistently it only marginally underpredicted the magnitude of the vertical displacements when the original permeability profiles were used, suggesting that the rate of consolidation was representative of that observed in the field. In Fig. 18 the numerical predictions for various degrees of the anisotropy of permeability of unit $\mathrm{A} 3_{\text {II }}$ are plotted together with the field measurements.

The presence of this more permeable sub-unit affects the profiles of the vertical movements in the longer term (i.e. after the construction of the EB tunnel). Not only does it result in greater maximum settlement, but also the higher is the degree of the permeability anisotropy, the wider the predicted trough becomes (although it is still not as wide as suggested by the field data). This is better illustrated in Fig. 19, where the improvement compared with the original permeability profile is apparent. However, when the degree of permeability anisotropy increases from 2 to 25 the improvement is much greater compared with when it increases from 25 to 100 . Referring to Fig. 18, the best estimate of long-term movements is given for the case where the degree of anisotropy at unit $\mathrm{A} 3_{\mathrm{II}}$ is 25 , as not only does it predict reasonably well the change of shape of the settlement trough and the magnitude of settlement for all the time periods considered, but it also widens the trough outside the area between the axes of the two tunnels. An additional line in the plots in Fig. 18 shows the settlements predicted once the consolidation process comes to its end, suggesting that marginal additional settlement is expected since the last available field measurement.

In Fig. 20 the settlement is plotted against time after construction of the EB tunnel, for positions that correspond to the $5 \mathrm{~m}$ depth level positions of extensometers (A-K) (see Fig. 2). The evolution of settlement predicted (from the analysis using the 'high both' calibration case and 25 as the degree of anisotropy of the permeability of sub-unit $\left.\mathrm{A} 3_{\mathrm{II}}\right)$ is in good agreement with the field data for the extensometers A to $\mathrm{H}$. The numerical predictions show the settlement evolving at the same rate for the first year after construction of the EB tunnel, but later marginally accelerating, resulting in a slight over-estimation of the soil movements.

\section{CONCLUSIONS}

The series of analyses presented in this paper explored in a detailed way the use of a modified two-surface kinematic 


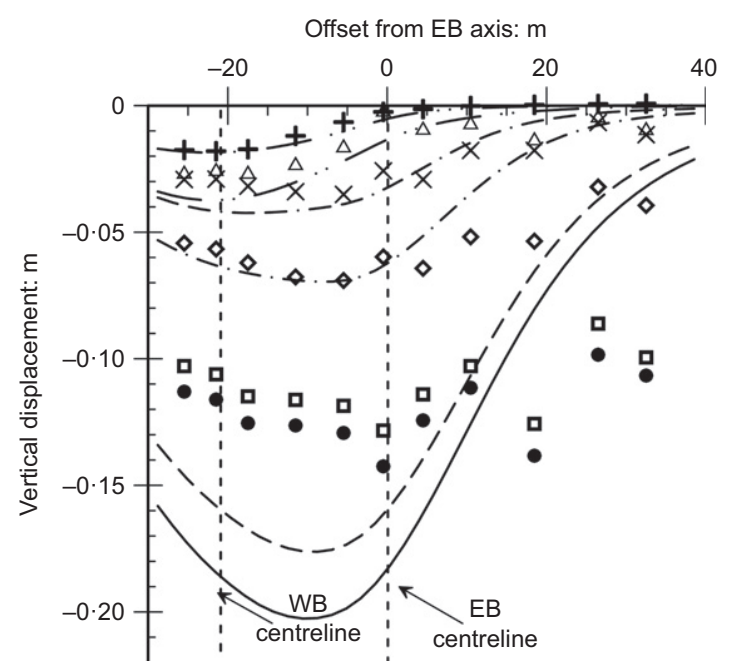

(a)

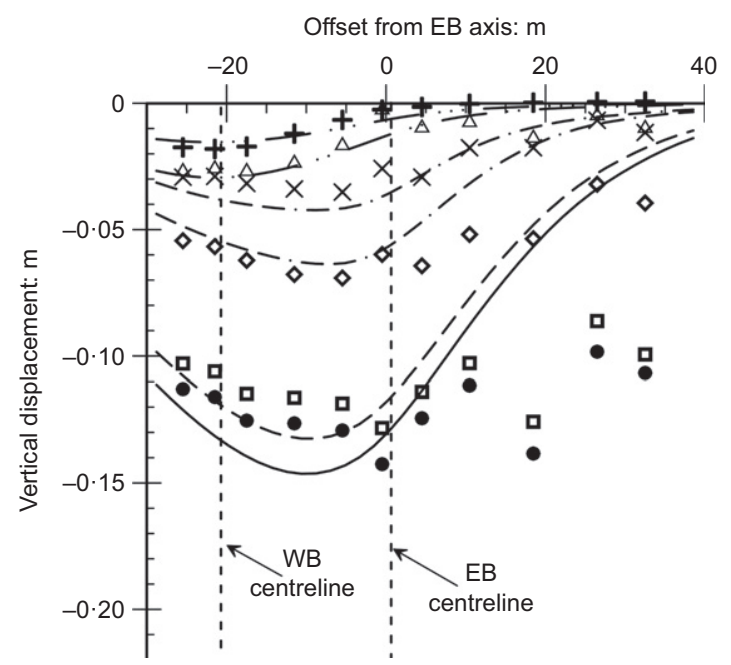

(c)

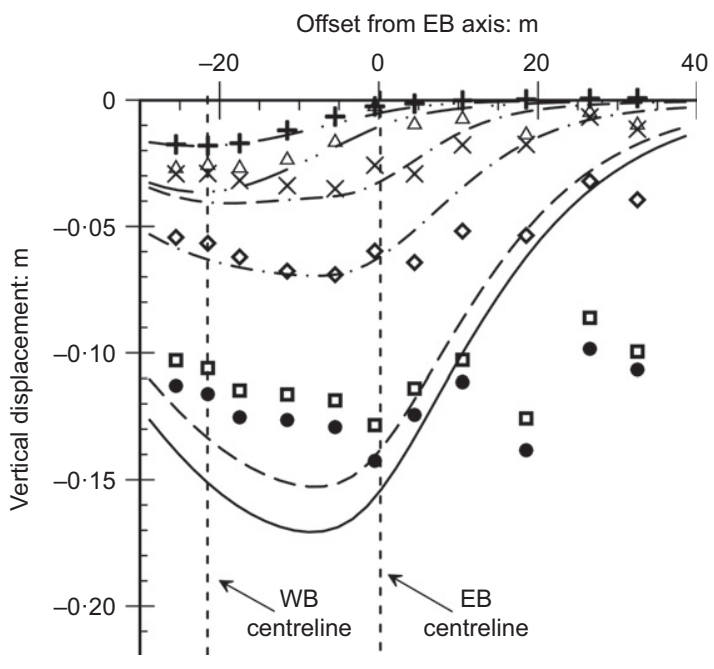

(b)

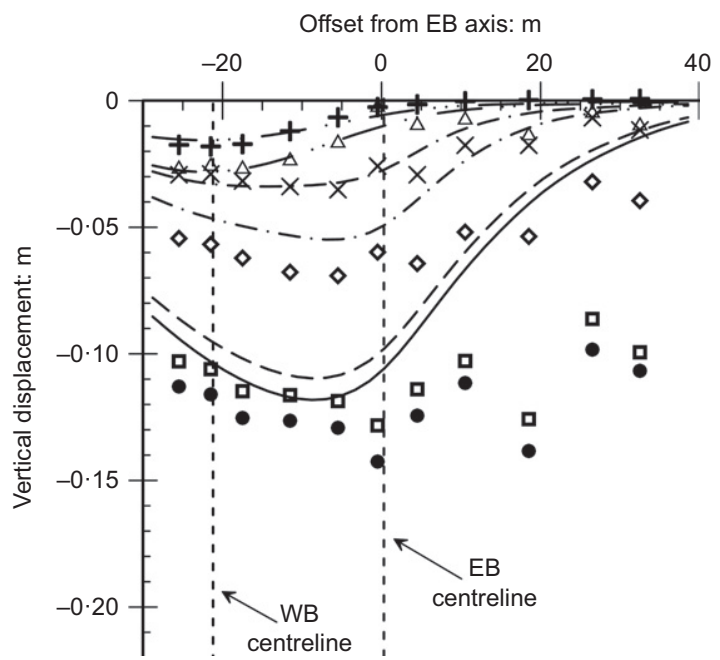

(d)

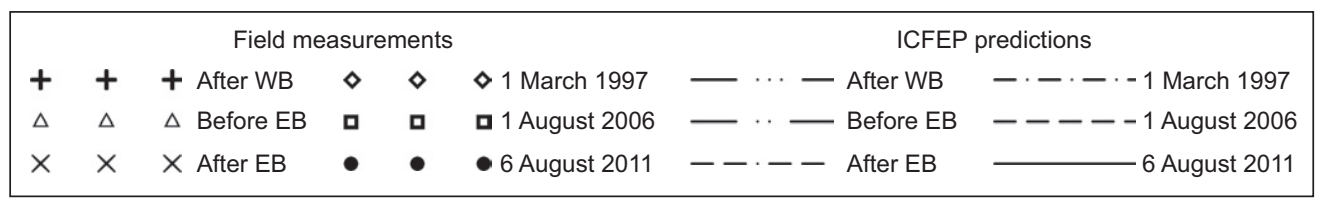

Fig. 17. Long-term settlement profiles for: (a) low triaxial; (b) high triaxial; (c) low both; (d) high both calibration cases

hardening model to predict ground response due to tunnelling, comparing results with measurements from the St James's Park case study.

The calibration of the model against experimental data from tests on intact samples showed that it cannot predict accurately results from both oedometer and undrained triaxial tests using the same parameter values. Modelling the previous stress history revealed that the $K_{0}$ and the yield stress ratio (YSR) profiles prior to analysing the effects of tunnel construction have to be consistent with the parameter values of the model calibrated using laboratory test data. Different calibrations resulted in different profiles of $K_{0}$ and YSR.

Predictions of the short-term soil displacements (vertical and horizontal) do not seem to be strongly controlled by the initial elastic stiffness, but the percentage of unloading does. The short-term response is controlled by how the stiffness changes with strain (i.e. how fast the stiffness degrades), implying that the shearing behaviour controls the short-term response. In addition it is shown that that the relative stiffness between compression and extension during tunnel excavation cannot be related to the different shapes of the surface settlement troughs. This was partly attributed to the different stiffness responses of elements further away from the tunnel boundary.

In the long term the consolidation behaviour dictates the soil movements. It was shown that a realistic anisotropic permeability profile must be used for accurate long-term predictions. Finally, sub-units of higher sand and silt concentrations inside the London Clay should be modelled with a higher degree of anisotropy of permeability for more realistic predictions.

The proposed methodology of using the modified twosurface kinematic hardening model for analysing tunnelling in London Clay has been proven to give very satisfactory predictions both in the short and the long term. Analysing different diameter tunnels, at different depths and for different volume loss values in London Clay with the same model parameters would generalise the findings for tunnelling in the London Clay and would be a clear indication that 


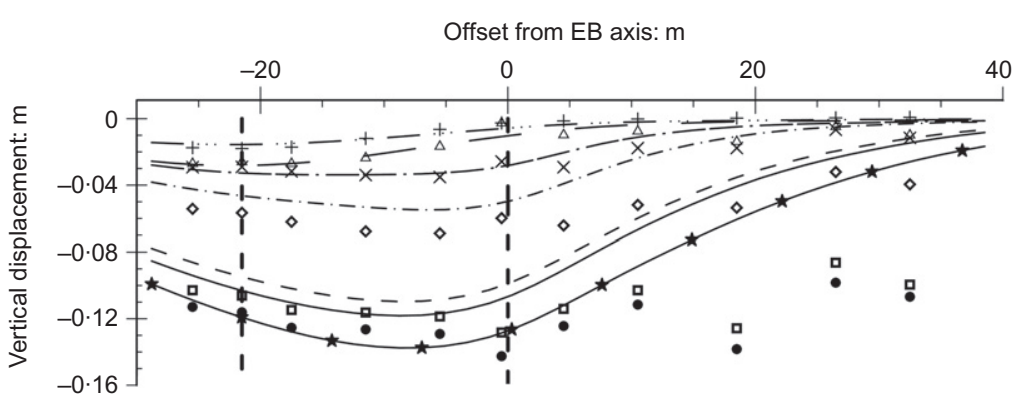

(a)

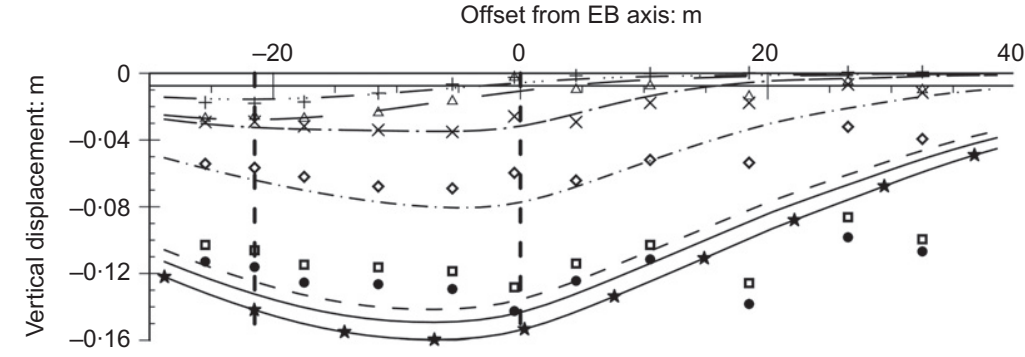

(b)

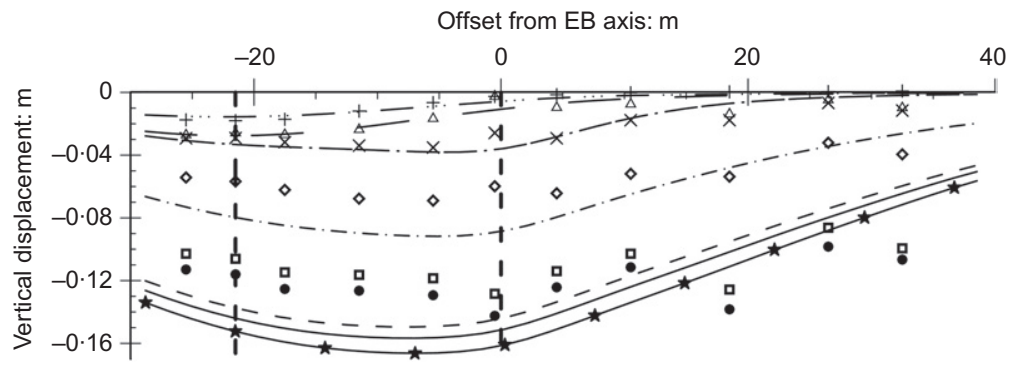

(c)

\begin{tabular}{|c|c|c|c|c|c|c|c|c|c|c|}
\hline \multirow{3}{*}{$\begin{array}{l}+ \\
\Delta\end{array}$} & & & \multicolumn{4}{|c|}{ Field measurements } & \multicolumn{4}{|c|}{ ICFEP predictions } \\
\hline & + & + & After WB & $\diamond$ & $\diamond$ & $\diamond 1$ March 1997 & 一 & - After WB & --- & 1 August 2006 \\
\hline & $\Delta$ & $\Delta$ & Before EB & a & व & ㅁ 1 August 2006 & - & Before EB & 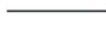 & 6 August 2011 \\
\hline$x$ & $x$ & $x$ & After EB & - & - & - 6 August 2011 & -- & $\begin{array}{l}-\cdot \text { After EB } \\
\text { - - } 1 \text { March } 1997\end{array}$ & & $\begin{array}{l}\text { End of } \\
\text { consolidation }\end{array}$ \\
\hline
\end{tabular}

Fig. 18. Profiles of vertical movement for (a) 2, (b) 25 and (c) 100 degrees of anisotropy of permeability of sub-unit $A 3_{\text {II }}$

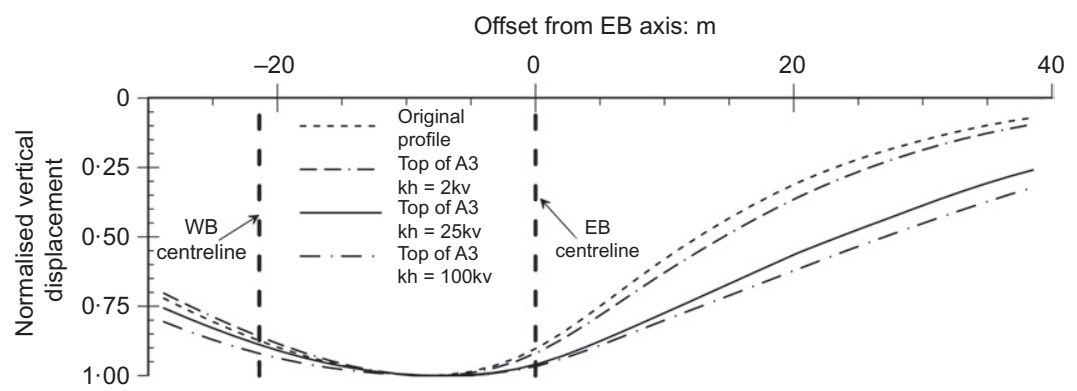

Fig. 19. Normalised settlement troughs for different degrees of permeability anisotropy of unit $A 3_{\text {II }}$ for the predictions on 6 August 2011 (kh, horizontal permeability; kv, vertical permeability)

the same methodology can be followed for other soils (at least those with roughly similar stress histories).

\section{ACKNOWLEDGEMENTS}

The authors wish to acknowledge the Engineering and Physical Sciences Research Council (EPSRC, research grant: EP/G063486/1), Crossrail and Morgan Sindall who were major sponsors of the research project at Imperial College. Many thanks are due to the Imperial College research team, in particular Professor John Burland and Dr Katerina Tsiampousi.

\section{NOTATION}

$A, n, m$ parameters for calculating the elastic shear modulus

$a$ coefficient of the hardening modulus $A$

$E_{\mathrm{d}}$ deviatoric strain

$E_{\text {usec }}$ secant undrained Young's modulus

$G_{\mathrm{e}} \quad$ elastic shear stiffness

$G_{\text {oct }}$ incremental shear stiffness

$J$ deviatoric stress, $\Xi=1 / \sqrt{ } 6\left[\left(\sigma_{1}^{\prime}-\sigma_{2}^{\prime}\right)^{2}+\left(\sigma_{2}^{\prime}-\sigma_{3}^{\prime}\right)^{2}+\left(\sigma_{3}^{\prime}-\sigma_{1}^{\prime}\right)^{2}\right]^{1 / 2}$

$K_{0} \quad$ coefficient of earth pressure coefficient at rest

$p^{\prime} \quad$ mean effective stress, $p^{\prime}=1 / 3\left(\sigma_{1}^{\prime}+\sigma_{2}^{\prime}+\sigma_{3}^{\prime}\right)$

$R$ ratio of the yield surface size to that of the bounding surface

$v$ angle of dilation 

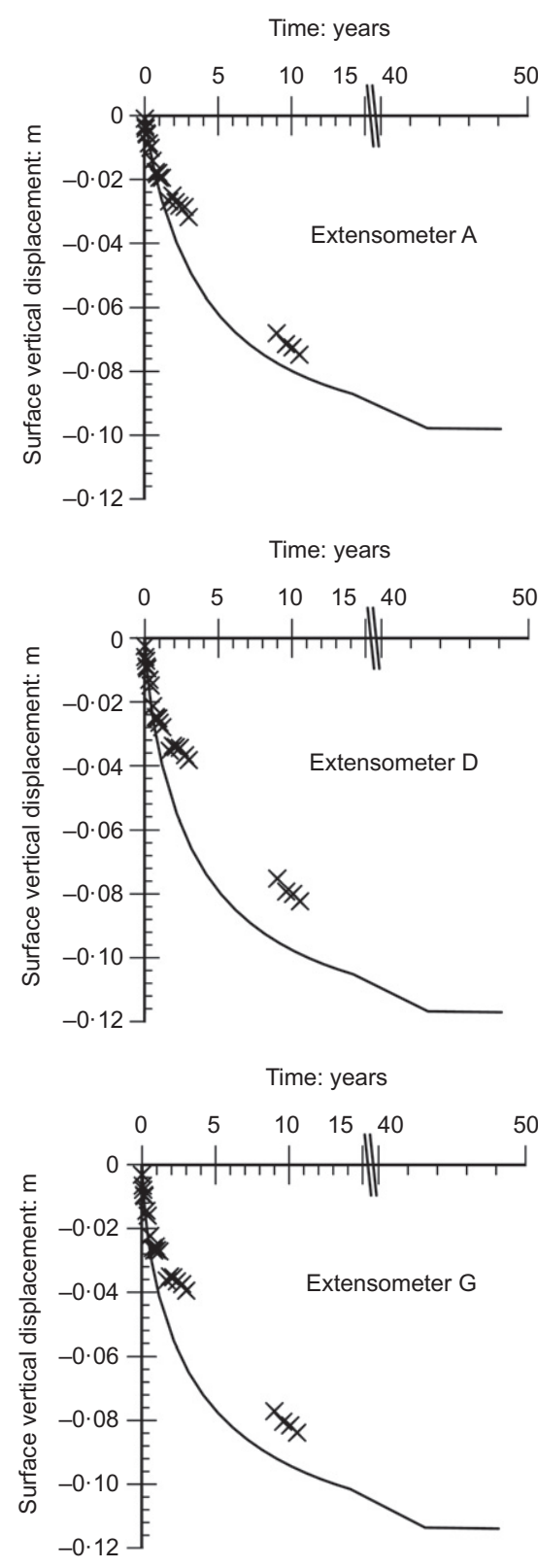

Time: years

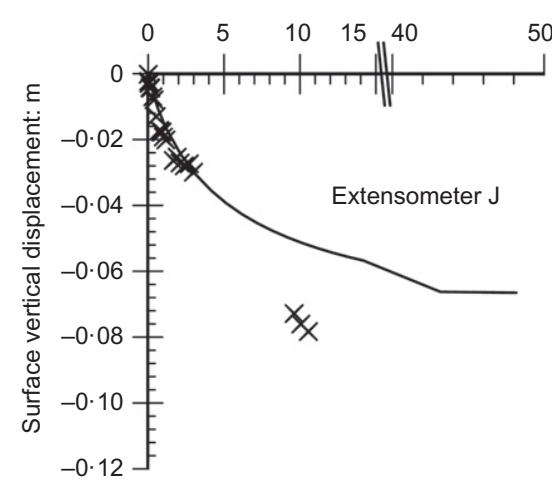

Time: years

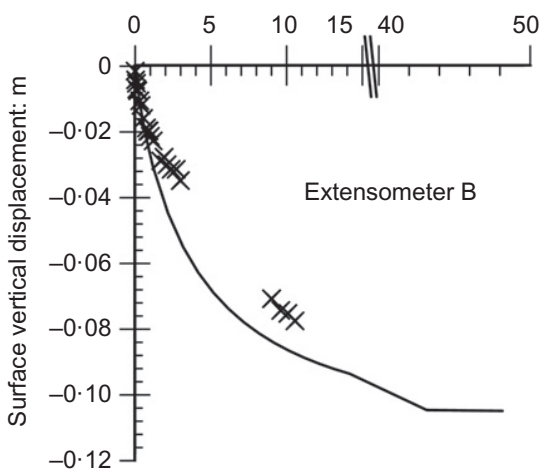

Time: years

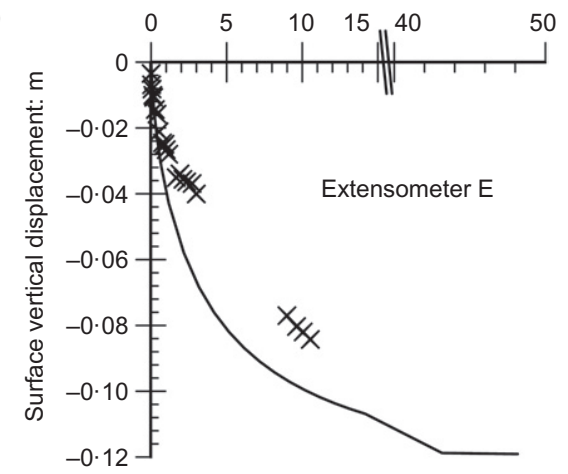

Time: years

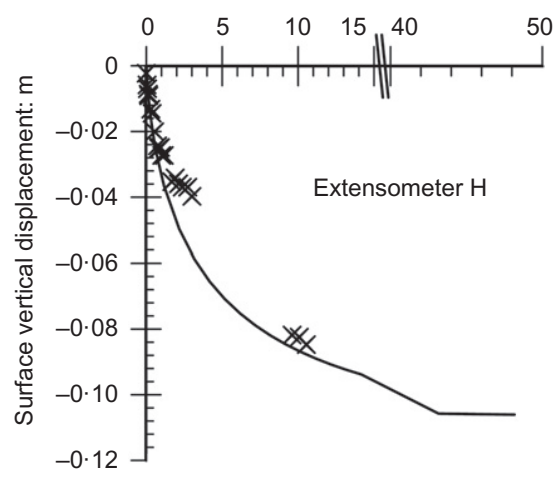

Time: years

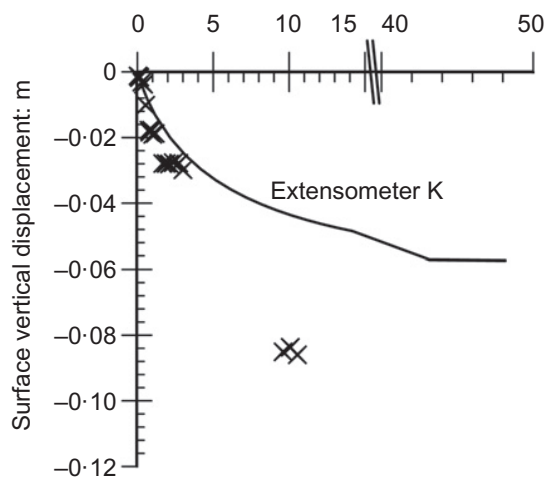

Time: years

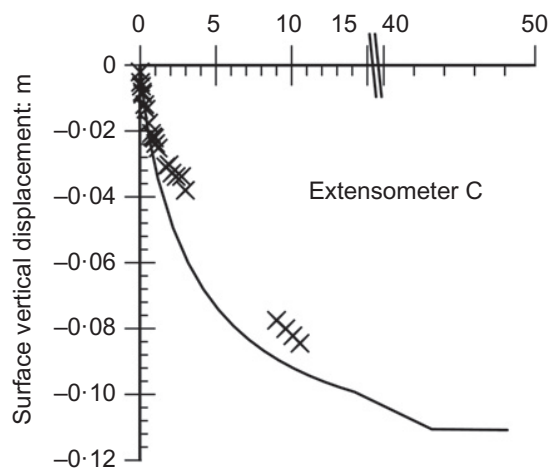

Time: years

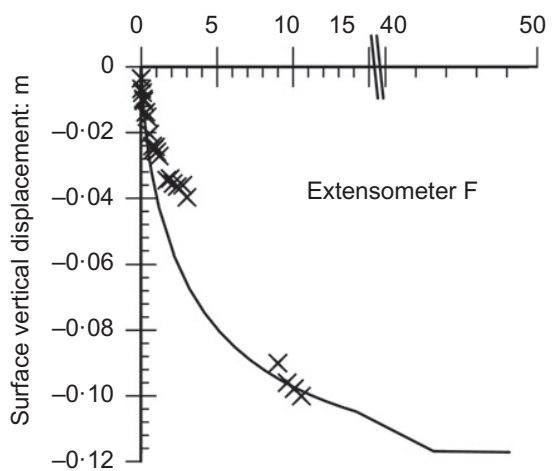

Time: years

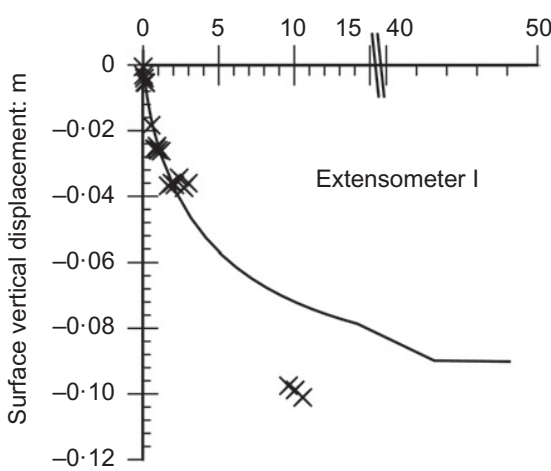

Fig. 20. Long-term settlement for the top of all the rod extensometers ( $5 \mathrm{~m}$ below ground level)

$v_{1} \quad$ specific volume at unit pressure in the $v-\ln p^{\prime}$ space

$\gamma$ bulk unit weight of soil

$\kappa$ slope of swelling lines in the $v-\ln p^{\prime}$ space approximated to be linear

$\kappa_{\mathrm{e}} \quad$ slope of elastic swelling lines in the $v-\ln p^{\prime}$ space

$\lambda$ slope of the normal compression line in the $v-\ln p^{\prime}$ space

$\varphi^{\prime}$ angle of internal shearing resistance defining the MohrCoulomb hexagon in the deviatoric plane

\section{REFERENCES}

Addenbrooke, T. I., Potts, D. M. \& Puzrin, A. M. (1997). The influence of pre-failure soil stiffness on the numerical analysis of tunnel construction. Géotechnique 47, No. 3, 693-712, http:// dx.doi.org/10.1680/geot.1997.47.3.693.

Al-Tabbaa, A. \& Wood, D. M. (1989). An experimental based 'bubble' model for clay. In Proceedings of international conference on numerical models in geomechanics (eds 
A. Pietruszczak and G. N. Pande), pp. 91-99. Rotterdam, the Netherlands: Balkema.

Atkinson, J. H., Richardson, D. \& Stallebrass, S. E. (1990). Effect of recent stress history on the stiffness of overconsolidated soil. Géotechnique 40, No. 4, 531-540, http://dx.doi.org/10.1680/ geot.1990.40.4.531.

Avgerinos, V. (2014). Numerical investigation of tunnelling beneath existing tunnels. $\mathrm{PhD}$ thesis, Imperial College, University of London, London, UK.

Burland, J. B. (1990). 30th Rankine Lecture: on the compressibility and shear strength of natural clays. Géotechnique 40, No. 3, 329-378, http://dx.doi.org/10.1680/geot.1990.40.3.329.

Burland, J. B., Simpson, B. \& St. John, H. D. (1979). Movements around excavations in London Clay. In Design parameters in geotechnical engineering: proceedings of the VII ECSMFE, 1979, Brighton, vol. 1, pp. 13-29. London, UK: BGS.

Clayton, C. R. I. \& Heymann, G. (2001). Stiffness of geomaterials at very small strains. Géotechnique 51, No. 3, 245-255, http:/l dx.doi.org/10.1680/geot.2001.51.3.245.

Franzius, J. N., Potts, D. M. \& Burland, J. B. (2005). The influence of soil anisotropy and $K_{0}$ on ground surface movements resulting from tunnel excavation. Géotechnique 55, No. 3, 189-199, http://dx.doi.org/10.1680/geot.2005.55.3.189.

Gasparre, A. (2005). Advanced laboratory characterisation of London Clay. PhD thesis, Imperial College, University of London, London, UK.

Gasparre, A. \& Coop, M. R. (2008). The quantification of the effects of structure on the compression of a stiff clay. Can. Geotech. J. 45, No. 9, 1324-1334.

Gasparre, A., Nishimura, S., Coop, M. R. \& Jardine, R. J. (2007a). The influence of structure on the behaviour of London Clay. Géotechnique 57, No. 1, 19-31, http://dx.doi.org/10.1680/geot. 2007.57.1.19.

Gasparre, A., Nishimura, S., Minh, N. A., Coop, M. R. \& Jardine, R. J. (2007b). The stiffness of natural London Clay. Géotechnique 57, No. 1, 33-47, http://dx.doi.org/10.1680/geot. 2007.57.1.33.

González, N. A., Rouainia, M., Arroyo, M. \& Gens, A. (2012). Analysis of tunnel excavation in London Clay incorporating soil structure. Géotechnique 62, No. 12, 1095-1109, http://dx.doi. org/10.1680/geot.11.P.030.

Grammatikopoulou, A. (2004). Development, implementation and application of kinematic hardening models for overconsolidated clays. $\mathrm{PhD}$ thesis, Imperial College, University of London, London, UK.

Grammatikopoulou, A., Zdravković, L. \& Potts, D. M. (2008). The influence of previous stress history and stress path direction on the surface settlement trough induced by tunnelling. Géotechnique 58, No. 4, 269-281, http://dx.doi.org/10.1680/ geot.2008.58.4.269.

Hight, D. W., Gasparre, A., Nishimura, S., Minh, N. A., Jardine, R. J. \& Coop, M. R. (2007). Characteristics of the London Clay from the Terminal 5 site at Heathrow airport. Géotechnique 57, No. 1, 3-18, http://dx.doi.org/10.1680/geot. 2007.57.1.3.

Jardine, R. J. (1995). One perspective of the pre-failure deformation characteristics of some geomaterials. In Proceedings of conference on pre-failure deformation of geomaterials (eds M. Shibuya and S. Miura), vol. 2, pp. 855-886. Rotterdam, the Netherlands: Balkema.

Jardine, R. J., Symes, M. J. \& Burland, J. B. (1984). The measurement of soil stiffness in the triaxial apparatus. Géotechnique 34, No. 3, 323-340, http://dx.doi.org/10.1680/ geot.1984.34.3.323.

King, C. (1981). The stratigraphy of London Basin and associated deposits, Tertiary research special paper no. 6. Rotterdam, the Netherlands: Backhuys.

Klar, A. \& Klein, B. (2014). Energy-based volume loss prediction for tunnel face advancement in clays Géotechnique 64, No. 10, 776-786, http://dx.doi.org/10.1680/geot.14.P.024.

Lambe, T. W. (1973). Predictions in soil engineering. Géotechnique 23, No. 2, 149-202, http://dx.doi.org/10.1680/geot.1973.23.2.151.

Mair, R. J. \& Taylor, R. N. (1997). Bored tunnelling in the urban environment: state of the art report and theme lecture. In Proceedings of 14 th international conference of soil mechanics and foundation engineering, Hamburg, Germany, pp. 2353-2385. Rotterdam, the Netherlands: Balkema.

Mašin, D. (2009). 3D Modelling of an NATM tunnel in high $K_{0}$ clay using two different constitutive models. J. Geotech. Geoenviron. Engng 135, No. 9, 1326-1335.

Mašin, D. \& Herle, I. (2005). Numerical analysis of a tunnel in London Clay using different constitutive models. Proceedings of the 5th international symposium TC28 on geotechnical aspects of underground construction in soft ground, Amsterdam, the Netherlands, pp. 595-600.

Mayne, P. W. \& Kulhawy, F. H. (1982). Ko-OCR relationships in soil. J. Geotech. Engng Div., ASCE 108, No. GT6, 851-872.

Nyren, R. J. (1998). Field measurements above twin tunnels in London Clay. PhD thesis, Imperial College, University of London, London, UK.

Nyren, R. J., Standing, J. R. \& Burland, J. B. (2001). Surface displacements at St James's Park greenfield reference site above twin tunnels through the London Clay. In Building response to tunnelling; vol. 2: case studies (eds J. B. Burland, J. R. Standing and F. M. Jardine), pp. 387-400. London, UK: Thomas Telford.

O'Reilly, M. P. \& New, B. M. (1982). Settlements above tunnels in the UK - their magnitude and prediction. Proceedings of tunnelling '82 (ed. M. J. Jones), pp. 173-181. London, UK: Institution of Mining and Metallurgy.

Osman, A., Bolton, M. \& Mair, R. (2006). Predicting 2D ground movements around tunnels in undrained clay. Géotechnique 56, No. 9, 597-604, http://dx.doi.org/10.1680/ geot.2006.56.9.597.

Peck, R. B. (1969). Deep excavations and tunnelling in soft ground. Proceedings of the 7th international conference on soil mechanics and foundation engineering, Mexico City, Mexico, state-of-the-art volume, pp. 225-290.

Pinto, F. \& Whittle, A. (2014). Ground movements due to shallow tunnels in soft ground. I: Analytical solutions. J. Geotech. Geoenviron. Engng 140, No. 4, 04013040.

Potts, D. M. \& Zdravković, L. (1999). Finite element analysis in geotechnical engineering: theory, vol. 1. London, UK: Thomas Telford.

Potts, D. M. \& Zdravković, L. (2001). Finite element analysis in geotechnical engineering: application, vol. 2. London, UK: Thomas Telford.

Puzrin, A. M., Burland, J. B. \& Standing, J. R. (2012). Simple approach to predicting ground displacements caused by tunnelling in undrained anisotropic elastic soil. Géotechnique 62, No. 4, 341-352, http://dx.doi.org/10.1680/geot.10.P.127.

Sagaseta, C. (1987). Analysis of undrained soil deformation due to ground loss Géotechnique 37, No. 3, 301-320, http://dx.doi.org/ 10.1680/geot.1987.37.3.301.

Salamanca Gallo, M. C. (2005). Long-term effect of tunnelling construction in London Clay. MSc dissertation, Imperial College, University of London, London, UK.

Schmidt, B. (1969). Settlements and ground movements associated with tunnelling in soil. $\mathrm{PhD}$ thesis, University of Illinois, Urbana, IL, USA.

Stallebrass, S. E. \& Taylor, R. N. (1997). The development and evaluation of a constitutive model for the prediction of ground movements in overconsolidated clay. Géotechnique 47, No. 2 , 235-253, http://dx.doi.org/10.1680/geot.1997.47.2.235.

Standing, J. R. \& Burland, J. B. (2006). Unexpected tunnelling volume losses in the Westminster area, London. Géotechnique 56, No. 1, 11-26, http://dx.doi.org/10.1680/geot.2006.56.1.11.

Standing, J. R., Nyren, R. J., Burland, J. B. \& Longworth, T. I. (1996). The measurement of ground movement due to tunnelling at two control sites along the Jubilee Line Extension. In Geotechnical aspects of underground construction in soft ground (eds R. J. Mair and R. N. Taylor), pp. 751-756. Rotterdam, the Netherlands: Balkema.

Verruijt, A. (1997). A complex variable solution for a deforming circular tunnel in an elastic half-plane. Int. J. Numer. Analyt. Methods Geomech. 21, No. 2, 77-89.

Zymnis, D. M., Chatzigiannelis, I. \& Whittle, A. J. (2013). Effect of anisotropy in ground movements caused by tunnelling Géotechnique 63, No. 13, 1083-1102, http://dx.doi.org/10.1680/ geot.12.P.056. 